\title{
Apoptosis Mediated by Fas but Not Tumor Necrosis Factor Receptor 1 Prevents Chronic Disease in Mice Infected with Murine Cytomegalovirus
}

\author{
Martin Fleck, ${ }^{\star \ddagger}$ Earl R. Kern, ${ }^{\S}$ Tong Zhou, ${ }^{\ddagger}$ Jürgen Podlech,, Winfried Wintersberger, ${ }^{\ddagger}$ Carl K. Edwards, III, \\ and John D. Mountz ${ }^{\ddagger}$ \\ *The University of Regensburg, Department of Medicine I, 93042 Regensburg, Germany; ${ }^{\ddagger}$ The University of Alabama at Birmingham, \\ Department of Medicine, Division of Clinical Immunology and Rheumatology, and the Veterans Administration Medical Center, \\ Birmingham, Alabama 35294; ${ }^{\$}$ The University of Alabama at Birmingham, Department of Pediatrics, Birmingham, Alabama 35294; \\ "The University of Mainz, Department of Virology, 55101 Mainz, Germany; and ${ }^{\mathbb{T}}$ Amgen, Inc., Department of Inflammation, Boulder, \\ Colorado 80301
}

\begin{abstract}
The role of Fas- and TNF-receptor 1 (TNF-R1)-mediated apoptosis in the clearance of virally infected cells and in the regulation of the immune response was analyzed after murine cytomegalovirus (MCMV) infection of C57BL/6 (B6)- $+/+$ mice, Fas-mutant B6-lpr/lpr mice, TNF-R1 knockout B6-tnfr ${ }^{0 / 0}$ mice, and double-deficient B6-tnfr ${ }^{0 / 0}$ lpr/lpr mice. There was approximately equivalent clearance of MCMV in $\mathrm{B} 6-+/+$, B6-tnfr ${ }^{0 / 0}$, and B6-lpr/lpr mice, and by day 28 no infectious virus could be detected in the liver, kidney, lung, or peritoneal exudate. However, delayed virus clearance was observed in B6-tnfr ${ }^{0 / 0}$ lpr/lpr mice. An acute inflammatory response occurred in the liver, lung, and kidney of all mice, which was most severe $7 \mathrm{~d}$ after MCMV infection, but resolved by day 28 in B6- $+/+$ and B6-tnfr ${ }^{0 / 0}$ mice, but not in B6-lpr/lpr or B6-tnfr ${ }^{0 / 0}$ lpr/lpr mice. These results indicate that apoptosis mediated by either Fas or TNF-R1 is sufficient for rapid clearance of the virus. However, apoptosis induced by Fas, but not TNF-R1, is required for the downmodulation of the immune response to the virus and prevention of a chronic inflammatory reaction. (J. Clin. Invest. 1998. 102:1431-1443.) Key words: apoptosis • MCMV • Fas • lpr mice • TNF-R1 knockout mice
\end{abstract}

\section{Introduction}

Infection with human cytomegalovirus $(\mathrm{CMV})^{1}$ leads to widespread disease in immunocompromised patients including

Address correspondence to John D. Mountz, M.D., Ph.D., The University of Alabama at Birmingham, Department of Medicine, Division of Clinical Immunology and Rheumatology, 701 South 19th Street, LHRB 473, Birmingham, AL 35294. Phone: 205-934-8909; FAX: 205-975-6648; E-mail: john.mountz@ccc.uab.edu

Received for publication 3 March 1998 and accepted in revised form 10 August 1998.

1. Abbreviations used in this paper: 7-AAD, 7-amino-actinomycin $\mathrm{D}$; AICD, activation-induced cell death; B6, C57BL/6; CMV, cytomegalovirus; ds, double strand; LCMV, lymphocytic choriomeningitis virus; lpr mice, lymphoproliferation mutation mice; MCMV, murine CMV; $\mathrm{RF}$, rheumatoid factor; TCR, T cell receptor; TDT, terminal deoxynucleotidyl transferase; TNF-R1, TNF receptor 1 ; tnfr $^{0 / 0}$ mice, TNF-R1 knockout mice; TUNEL, TDT-mediated dUTP nick end labeling.

J. Clin. Invest.

(C) The American Society for Clinical Investigation, Inc. 0021-9738/98/10/1431/13 \$2.00

Volume 102, Number 7, October 1998, 1431-1443

http://www.jci.org hepatitis, pneumonitis, nephritis, retinitis, encephalitis, and colitis. Severe opportunistic CMV infections are especially common in transplant recipients and HIV-infected patients and are associated with significant mortality (1). Murine CMV (MCMV) has homology to certain regions of CMV (2) and MCMV infection in mice exhibits a similar course of infection to that in humans with regard to the establishment of acute and chronic infection, viral persistency and latency, and the host immune response $(3,4)$.

MCMV infection induces a primary immune response within the host involving macrophages, natural killer cells, and $\mathrm{T}$ and B lymphocytes (5-9). However, diverse mechanisms have evolved in MCMV, as well as other herpes viruses, to promote escape from immune surveillance and to enhance establishment of a latent infection (10-14). Prevention of apoptosis in the host cell has been proposed to be one important strategy by which viruses overcome the immune response (11, $15,16)$. This concept is supported by the recent identification of an increasing number of virus-encoded proteins that can inhibit different pathways of apoptosis in vitro including p53/ $\mathrm{pRb}$, the bcl-2 family, and molecules of the tumor-necrosis-factor receptor (TNF-R) superfamily, notably Fas (CD95/Apo-1) and TNF-R1 (CD120a) (11, 15). Inhibition of these pathways may not only prevent viral-induced apoptosis, but also block the cytotoxic $\mathrm{T}$ cell response mediated by $\mathrm{TNF}-\alpha$, Fas ligand, and perforin (17-20). These data suggest that apoptosis induced by Fas and TNF-R1 is important for limiting virus replication and spreading and is regulated by both viral proteins and the host defense system.

The physiological importance of Fas-mediated apoptosis became evident through the identification of the lpr mutations of the fas gene and the gld mutation of the fas ligand gene, which lead to lymphoproliferation and systemic autoimmune disease in mice homozygous for these mutations (21). Although all strains of mice that are homozygous for the lpr gene develop autoimmune disease, the disease phenotype and severity also depend on the genetic background and environmental factors $(21,22)$. C57BL/6 (B6)-lpr/lpr mice develop a milder autoimmune disease of later onset. They exhibit glomerulonephritis after $\sim 6-8$ mo of age but do not develop significant lung or liver disease (23). TNF-R1 and Fas show homology and share a homologous intracellular death domain that uses some of the same cytoplasmic signaling proteins (24, 25). Interaction of TNF- $\alpha$ with TNF-R 1 and TNF-R 2 plays a bifunctional role during an immune response since TNF- $\alpha$ is involved in the clearance of cells either through direct lysis (26, 27 ), acting as a proinflammatory cytokine (28), or by synergism with antiviral activity of other cytokines including IFN- $\gamma$ (29). Also, previous data indicate that $\mathrm{TNF}-\alpha$ is very important in promoting the inflammatory process after infection with 
MCMV (8). Both TNF-R1 and Fas have been shown to mediate activation-induced cell death (AICD) in T cells, B cells, and macrophages (19, 30-35). Fas and TNF-R1 double-deficient mice exhibit accelerated lymphoproliferation and increased autoimmune disease, which is associated with high mortality, indicating that the Fas and TNF-R1 signaling and apoptosis pathways may compensate for each other (23).

Previous studies using the murine model of lymphocytic choriomeningitis virus (LCMV) infection and mice carrying $\mathrm{T}$ cell receptor (TCR) transgenes suggest that the Fas-Fas ligand interaction is not required for peripheral deletion of $\mathrm{CD}^{+} \mathrm{T}$ cells, and the clearance of LCMV transgenic effector T cells has been found to occur in a Fas-independent fashion (36). However, T cells of LCMV-infected, Fas-deficient lpr mice exhibited decreased susceptibility to TCR-induced apoptosis in vitro (37). Furthermore, Fas-dependent control of peripheral clonal deletion of $\mathrm{V} \beta 6^{+} \mathrm{CD} 4^{+} \mathrm{T}$ cells has been demonstrated in vivo by infection of $l p r / l p r$ and $+/+$ mice with mouse mammary tumor virus expressing the viral superantigen SAG (38). Therefore, the role of Fas-mediated apoptosis in the peripheral deletion of activated $\mathrm{T}$ lymphocytes during a primary immune response after virus infections is controversial.

To determine the significance of apoptosis mediated by Fas and TNF-R1 in the clearance of virally infected cells and in the regulation of the immune response, B6- $+/+$ mice, B6-lpr/lpr mice, TNF-R1 knockout (B6-tnfr ${ }^{0 / 0}$ ), and TNF-R1 knockout Fas-deficient (B6-tnfro/0 lpr/lpr) mice were inoculated intraperitoneally with MCMV. The present results indicate that apoptosis mediated by either Fas or TNF-R1 is sufficient for rapid elimination of MCMV-infected cells. However, apoptosis mediated by Fas, but not by TNF-R1, is critical for downmodulation of the immune response, and defective expression of Fas leads to a chronic inflammatory disease after MCMV infection despite the absence of infectious virus.

\section{Methods}

Animals. 10-14-wk-old, female B6- $+/+$ mice and B6-lpr/lpr mice were obtained from The Jackson Laboratories (Bar Harbor, ME). B6-tnfro/0 mice and B6-tnfr ${ }^{0 / 0} l p r / l p r$ were generated as described previously (23) and were bred and maintained in our own animal facility at the University of Alabama at Birmingham under pathogen-free conditions.

Virus and virus titration. Female Balb/c mice were inoculated intraperitoneally with MCMV strain Smith obtained from the American Type Culture Collection (Rockville, MD) and salivary glands were collected $12 \mathrm{~d}$ later. The salivary glands were homogenized in MEM (GIBCO BRL, Grand Island, NY) containing 10\% FBS, and centrifuged. The supernatant was dispensed into aliquots, which were stored at $-80^{\circ} \mathrm{C}$ and used as the MCMV stock virus pool $\left(3 \times 10^{7}\right.$ $\mathrm{PFU} / \mathrm{ml}$ ). For the determination of the virus titer in tissues, organs were removed and homogenized as $10 \%$ (wt/vol) suspensions in DME (GIBCO BRL) supplemented with L-glutamine, 10\% FCS, penicillin/streptomycin, and amphotericin B. The homogenates were titrated as duplicates in $\log _{10}$ dilutions on subconfluent primary murine embryo fibroblasts in 12-well plates. $7 \mathrm{~d}$ later, monolayers were stained with neutral red and the number of plaques was counted.

Histological assessment and immunophenotyping. Organs were removed and fixed in $10 \%$ phosphate-buffered formalin. After paraffin embedding, tissue sections were cut $(5 \mu \mathrm{m})$ and stained with hematoxylin and eosin for morphological evaluation. Histopathologic scoring was performed by rating the severity of lesions and infiltration on a scale from 0 to 5 . The following criteria were applied for the grading scale: 0: normal histology; 1: minimal mononuclear cell infiltration with or without minimal cell destruction; 2 : modest mononuclear cell infiltration with 1-2 clear foci per field of view with focal cellular destruction; 3 : numerous aggregates (3-5) of mononuclear cells per field of view with destruction of liver, kidney, or lung tissue at several locations; 4: severe infiltration with mononuclear cells in multiple foci per lobe with destruction of liver, kidney, or lung tissue; and 5: diffuse infiltration with mononuclear cells with most severe cellular destruction. The histopathology was scored by three blinded observers, and the score represents the mean, with error bars representing the standard error of the mean (SEM).

For immunohistochemistry, slides were first incubated with a peroxidase-conjugated monoclonal antibody specific for TCR/CD3 (Dako, Glostrup, Denmark) or a biotin-conjugated monoclonal antibody specific for B220 (PharMingen, San Diego, CA). The biotinylated antibody specific for B220 was detected by application of peroxidase-conjugated streptavidin (Sigma Chemical Co., St. Louis, MO). Positive reactions were revealed using DAB substrate (Sigma) and methyl green was used for counterstaining.

Terminal deoxynucleotidyl transferase (TDT)-mediated dUTP nick end labeling (TUNEL). The method was modified slightly from that described previously (39). In brief, formalin-fixed and paraffinembedded tissue sections were deparaffinized and rehydrated. After thorough washing with deionized water, the tissue sections were subjected to permeabilization with proteinase $\mathrm{K}(10 \mu \mathrm{g} / \mathrm{ml}$, room temperature for $15 \mathrm{~min})$, and then incubated with freshly prepared TDT reaction mix (0.4 U/liter TDT, $10 \mathrm{nM}$ digitonigen modified-dUTP, and TDT buffer, which were purchased from Boehringer Mannheim, Indianapolis, IN) at $37^{\circ} \mathrm{C}$ for $60 \mathrm{~min}$. The incorporated digitonigendUTP was detected by incubation with alkaline phosphatase-conjugated antidigitonigen antibody at room temperature for $60 \mathrm{~min}$ and positive reactions were revealed using NBT/BCIP substrate. Methyl green was used for counterstaining.

7-amino-actinomycin $D(7-A A D)$ staining. For discrimination of apoptotic and nonapoptotic cells, tissue was harvested and single cell suspension was stained with $20 \mu \mathrm{g} / \mathrm{ml}$ of 7-AAD (Calbiochem, San Diego, CA) in PBS on ice for $30 \mathrm{~min}$ in the dark as described previously $(40,41)$. After washing with PBS, cells were fixed in $1 \%$ paraformaldehyde supplemented with $10 \mu \mathrm{g} / \mathrm{ml}$ actinomycin D. 10,000 nongated cells were analyzed using FACScalibur ${ }^{\circledR}$ (Becton Dickinson, Mountain View, CA).

Cytokine assays. Serum levels of IFN- $\gamma$ and TNF- $\alpha$ were determined using specific standard ELISA (Endogen, Woburn, MA). The sandwich ELISA were performed according to the manufacturer's protocol. The sensitivities of the IFN- $\gamma$ and TNF- $\alpha$ ELISA were $<15$ and $<10 \mathrm{pg} / \mathrm{ml}$, respectively.

Quantitation of autoantibodies. Serum levels of anti-double strand (ds) DNA antibodies and rheumatoid factor (RF) were determined by sandwich ELISAs as described previously (42). Sera samples were obtained from five mice per group of uninfected and infected mice. In brief, for quantitation of anti-dsDNA antibodies 96-well microtiter plates were precoated with $10 \mu \mathrm{g} / \mathrm{ml}$ of poly-L-lysine followed by 10 $\mu \mathrm{g} / \mathrm{ml}$ of dsDNA or $10 \mu \mathrm{g} / \mathrm{ml}$ of poly-L-glutamic acid as background control. For detection of RF, 96-well microtiter plates were coated with $4 \mu \mathrm{g} / \mathrm{ml}$ of affinity-purified rabbit $\operatorname{IgG}$ (all reagents were obtained from Sigma). The sera were diluted at 1:100 and incubated at room temperature for $4 \mathrm{~h}$. Bound anti-dsDNA antibodies or RF were detected by an IgG isotype-specific alkaline phosphatase-conjugated goat anti-mouse Ig (PharMingen). $P$-nitrophenylphosphate (Sigma) was used as substrate, and the color development was measured at $405 \mathrm{~nm}$ using an Emax microplate reader (Molecular Devices, Menlo Park, CA).

\section{Results}

Combined defect in Fas- and TNF-R1-mediated apoptosis delayed clearance of MCMV. To determine the role of Fas- and TNF-R1-mediated apoptosis in virus clearance, B6-+/+ mice, 
B6-lpr/lpr mice, B6-tnfr $r^{0 / 0}$, and B6-tnfro/0 lpr/lpr mice were inoculated intraperitoneally with MCMV. At different time points after infection, the presence of infectious MCMV in the organs was evaluated using a plaque assay. Consistent with previous reports, the clearance of MCMV occurred rapidly and efficiently in the liver, kidney, lung, and peritoneal exudate of B6- $+1+$ mice $(4,43,44)$. Almost equivalent clearance of MCMV was found in B6-lpr/lpr and B6-tnfr ${ }^{0 / 0}$ mice since by day 14 only the lung of B6-lpr/lpr mice harbored small amounts of infectious MCMV. By day 28, infectious MCMV was not detectable in the liver, kidney, lung, or peritoneal exudate of B6- $+/+$, B6-lpr/lpr, or B6-tnfr ${ }^{0 / 0}$ mice (Fig. 1). However, higher titers of virus and delayed virus clearance were found in the lung, kidney, and peritoneal exudate of B6-tnfr $r^{0 / 0}$ lpr/lpr mice, indicating that either Fas or TNF-R1 is sufficient for rapid clearance of MCMV. They may compensate for each other in the elimination of MCMV-infected cells.

$M C M V$ infection-induced chronic disease in Fas-mutant lpr/lpr mice. B6- $+/+$ mice, B6-tnfr ${ }^{0 / 0}$ mice, B6-lpr/lpr mice, and B6-tnfr $r^{0 / 0} l p r / l p r$ mice were inoculated intraperitoneally with MCMV. Histological examination performed $7 \mathrm{~d}$ after infection revealed an acute inflammatory response in the liver, kidney, and lung, which was most severe in B6- $+/+$ and B6lpr/lpr mice (Fig. 2, $A-C$ ). Multifocal hepatitis, interstitial and mesangial nephritis, and interstitial pneumonitis were present in B6- $+/+$ and B6-lpr/lpr mice, whereas B6-tnfro/0 mice exhibited only moderate inflammation, indicating the central role of $\mathrm{TNF}-\alpha$ in mediating an inflammatory response. After $4 \mathrm{wk}$, the inflammation had resolved in the organs of B6- $+/+$ mice and B6-tnfr ${ }^{0 / 0}$ mice (Fig. 2, $A-C$ ). In contrast, moderate inflammation was still present in B6-tnfr ${ }^{0 / 0} l p r / l p r$ mice, and a severe chronic inflammatory response was observed in the liver, kidney, and lung of B6-lpr/lpr mice, which persisted for over $100 \mathrm{~d}$ after infection, and $70 \mathrm{~d}$ after the clearance of infectious
MCMV (Fig. 2 D). The chronic hepatitis in B6-lpr/lpr mice was characterized by moderate multifocal degeneration and regeneration of hepatocytes with infiltration of mononuclear cells. Typical features of interstitial pneumonitis were found during the chronic phase of disease in the lung including thickening of the alveolar septa, hyperplasia of alveolar macrophages, and perivascular and peribronchial lymphocytic infiltrates. Severe proliferative glomerulonephritis with multifocal tubular degeneration and a lymphocytic infiltration in the interstitium indicated a chronic nephritis (Fig. 2, $A-C$ ). Thus, Fas-mediated apoptosis is required for the downmodulation of the inflammatory response induced by MCMV.

Immunophenotype of infiltrating cells. There were numerous $\mathrm{CD}^{+} \mathrm{T}$ lymphocytes among the infiltrating cells found during the acute inflammatory response in liver and lung of B6- $+/+$ mice (Fig. $3 A$ ) and B6-lpr/lpr mice. Furthermore, the infiltrates observed during the chronic phase of inflammation in the liver, kidney, and lung of B6-lpr/lpr mice consisted predominantly of $\mathrm{CD}^{+} \mathrm{T}$ lymphocytes (Fig. $3 \mathrm{~B}$ ). The majority of these infiltrating $\mathrm{T}$ cells did not coexpress B220 and therefore do not correspond to the TCR- $\alpha \beta^{+} \mathrm{CD} 4^{-} 8^{-} \mathrm{B} 220^{+} \mathrm{T}$ cell subpopulation which causes lymphoproliferation in $l p r / l p r$ mice. Only low numbers of cells stained positive for B220 in the liver and lung of B6-lpr/lpr mice $28 \mathrm{~d}$ after MCMV infection, indicating that the chronic inflammatory disease in B6-lpr/lpr mice was associated with an increased percentage of normal phenotype $\mathrm{CD}^{+} \mathrm{T}$ cells (Fig. $3 C$ ).

Apoptotic cells in situ after infection with $M C M V$. For detection of apoptosis in situ, liver tissue of MCMV-infected B6$+/+$, B6-lpr/lpr, and B6-tnfr ${ }^{0 / 0}$ mice was obtained at days 3, 7, 28, and 100. Apoptotic cells were identified using the TUNEL technique. At day 3 after MCMV infection, numerous cells undergoing apoptosis could be observed in all of the mice. These apoptotic cells were mainly located in separated clusters,

\section{Virus Titer in MCMV Infected Mice}

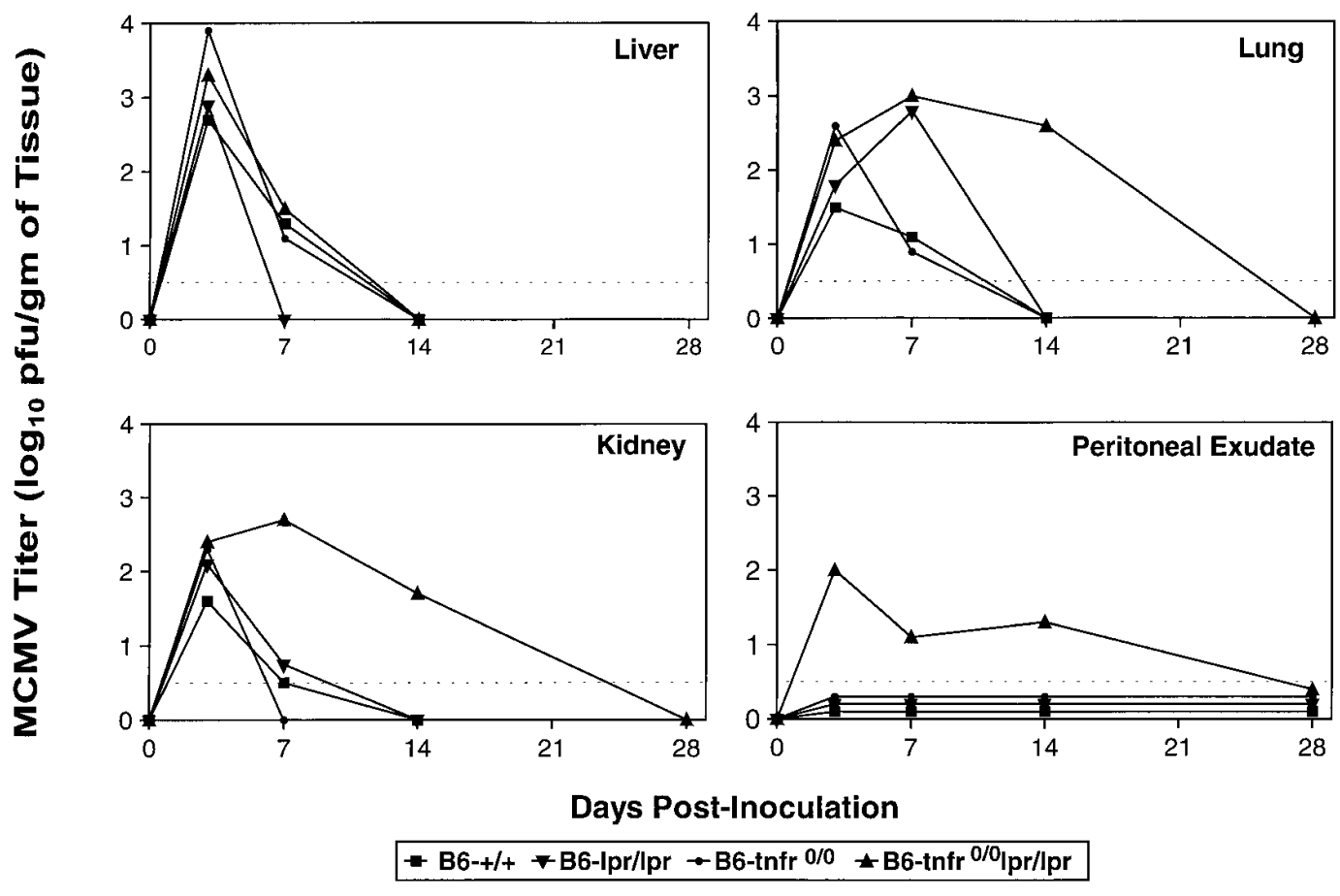

Figure 1. Delayed clearance of MCMV in Fas and TNF-R1 double-deficient mice. B6- $+/+$, B6-lpr/lpr, and B6-tnfro/0, and B6tnfr $r^{0 / 0} \mathrm{lpr} / \mathrm{lpr}$ mice were inoculated intraperitoneally with MCMV (10 PFU). Quantitation of infectious MCMV in liver, kidney, lung, and peritoneal exudate was performed at different time points using a plaque assay. 


\section{Liver ( x 80)}

\section{Day 7}
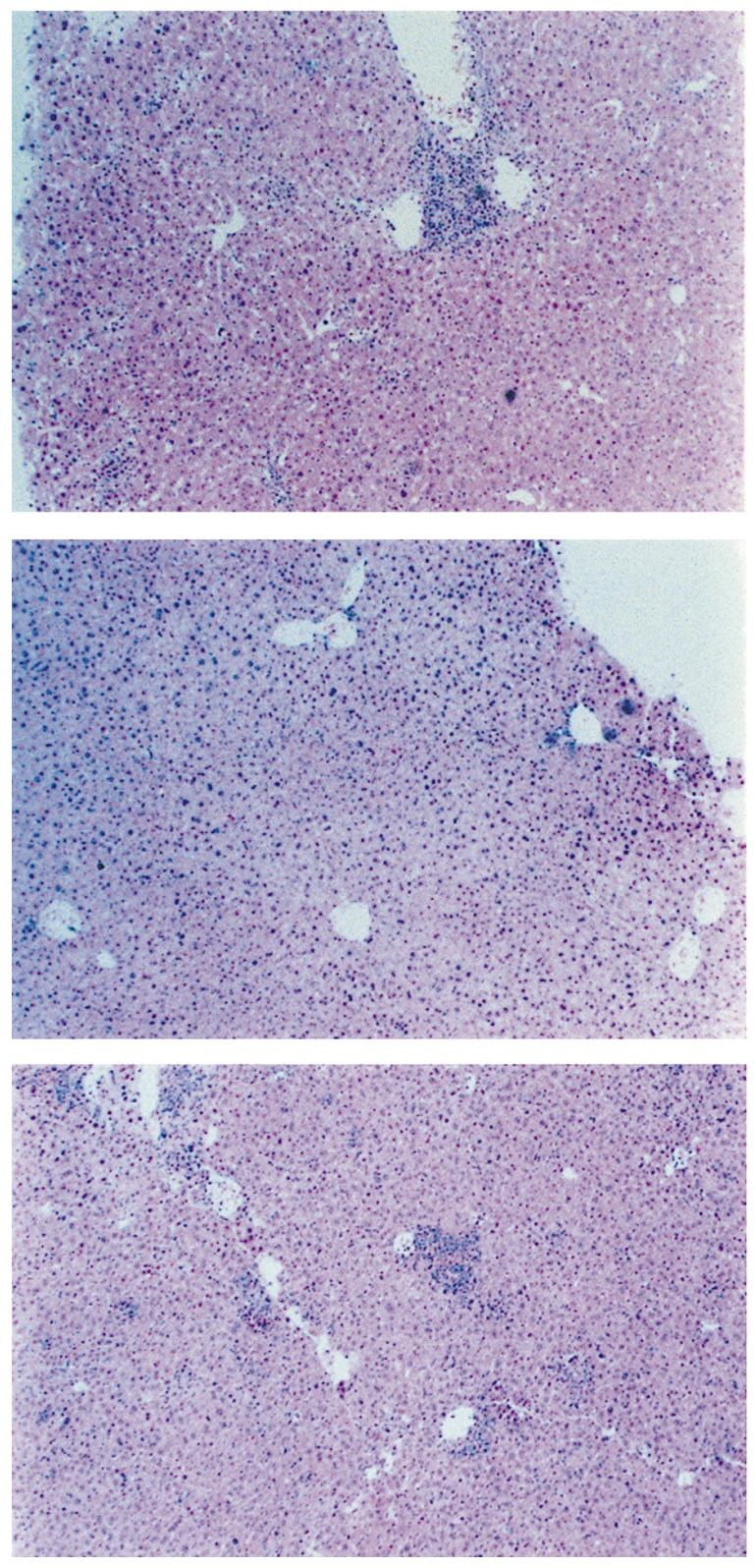

Day 28
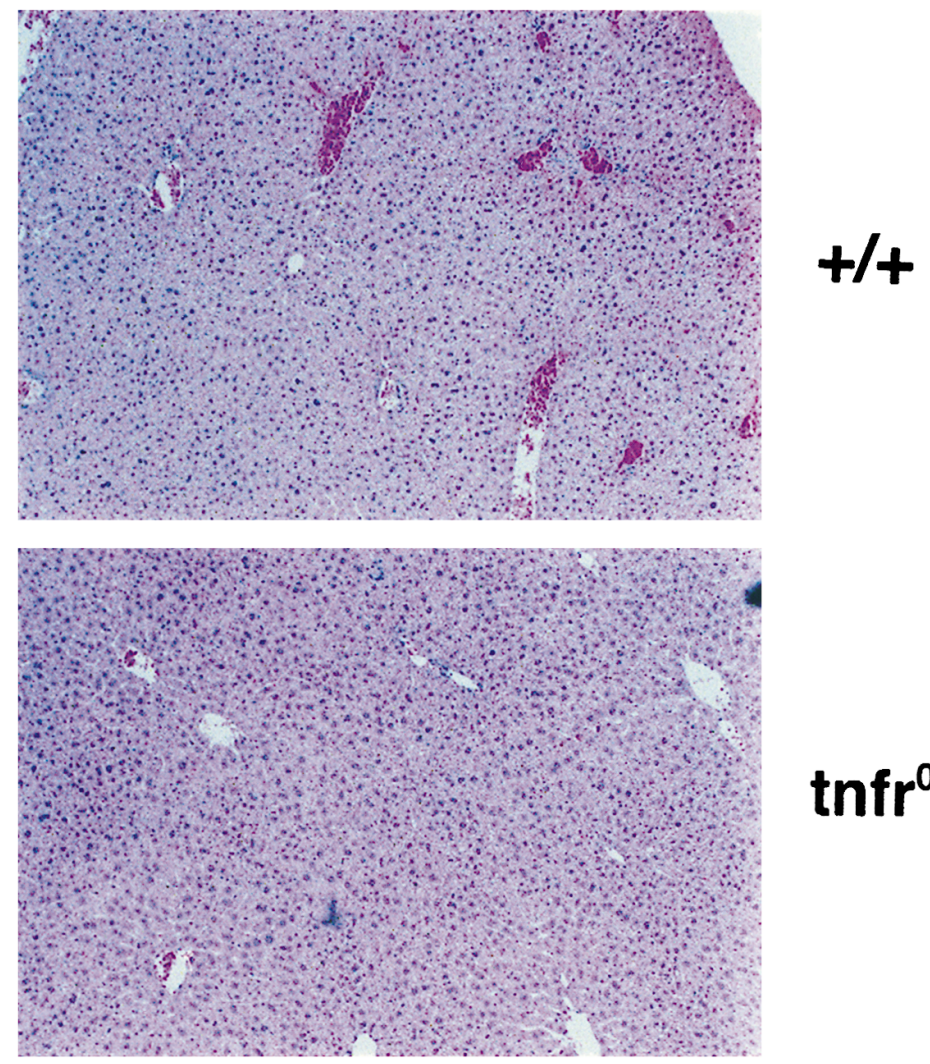

$\operatorname{tnfr}^{0 / 0}$

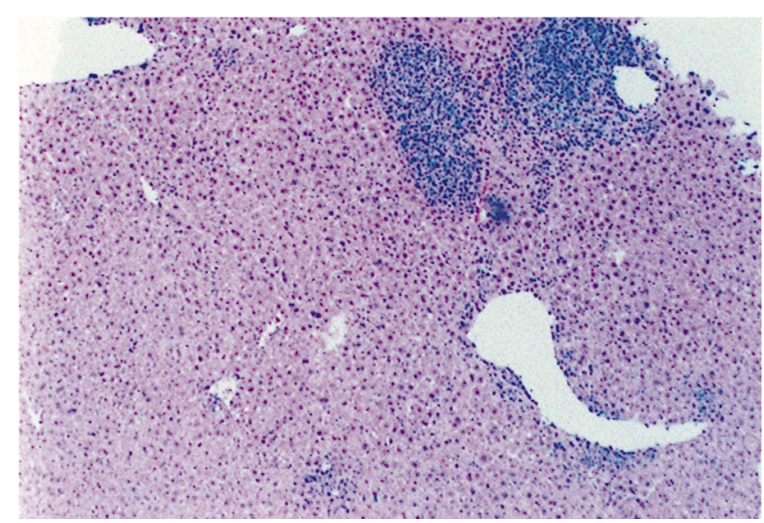

Ipr/lpr

Figure 2. MCMV infection-induced chronic disease in B6-lpr/lpr mice. B6- $+/+$ mice, B6-tnfr ${ }^{0 / 0}$ mice, B6-lpr/lpr mice, and B6-tnfr $r^{0 / 0} l p r / l p r$ mice were inoculated intraperitoneally with MCMV $\left(10^{5} \mathrm{PFU}\right)$. Histological evaluation was performed at days 7 and 28 after infection $(A-C)$ and day $100(D)$ (original magnification of 10 ), and tissues were assessed for severity of inflammation and tissue damage on a relative scale ranging from 0 (not present) to 5 (most severe) $(D)$. The severe chronic inflammatory response observed in B6-lpr/lpr mice was characterized by multifocal hepatitis $(A)$, interstitial and mesangial nephritis $(B)$, and interstitial pneumonitis $(C)$.

which contained apoptotic hepatocytes and inflammatory cells. Some cells displayed morphological features characteristic of MCMV infection, including cell rounding and nuclear inclusions (Fig. 4). Higher numbers of apoptotic cells were present $7 \mathrm{~d}$ after MCMV infection, and these apoptotic cells were both localized in foci and also occurred as scattered, individual cells throughout the liver tissue of B6-+/+ and B6-lpr/ lpr mice. The number of scattered apoptotic cells was especially high in B6-tnfr $r^{0 / 0}$ mice. Large numbers of apoptotic cells also were observed in the areas of accumulation of infiltrating cells in B6- $+/+$ mice. In contrast, the amount of apoptosis among infiltrating cells remained low in B6-lpr/lpr mice. There were no inflammatory cells and few apoptotic cells in the liver tissue 28 and $100 \mathrm{~d}$ after MCMV infection in B6-+/+ and B6- 


\section{Kidney ( x 80)}

\section{Day 7}
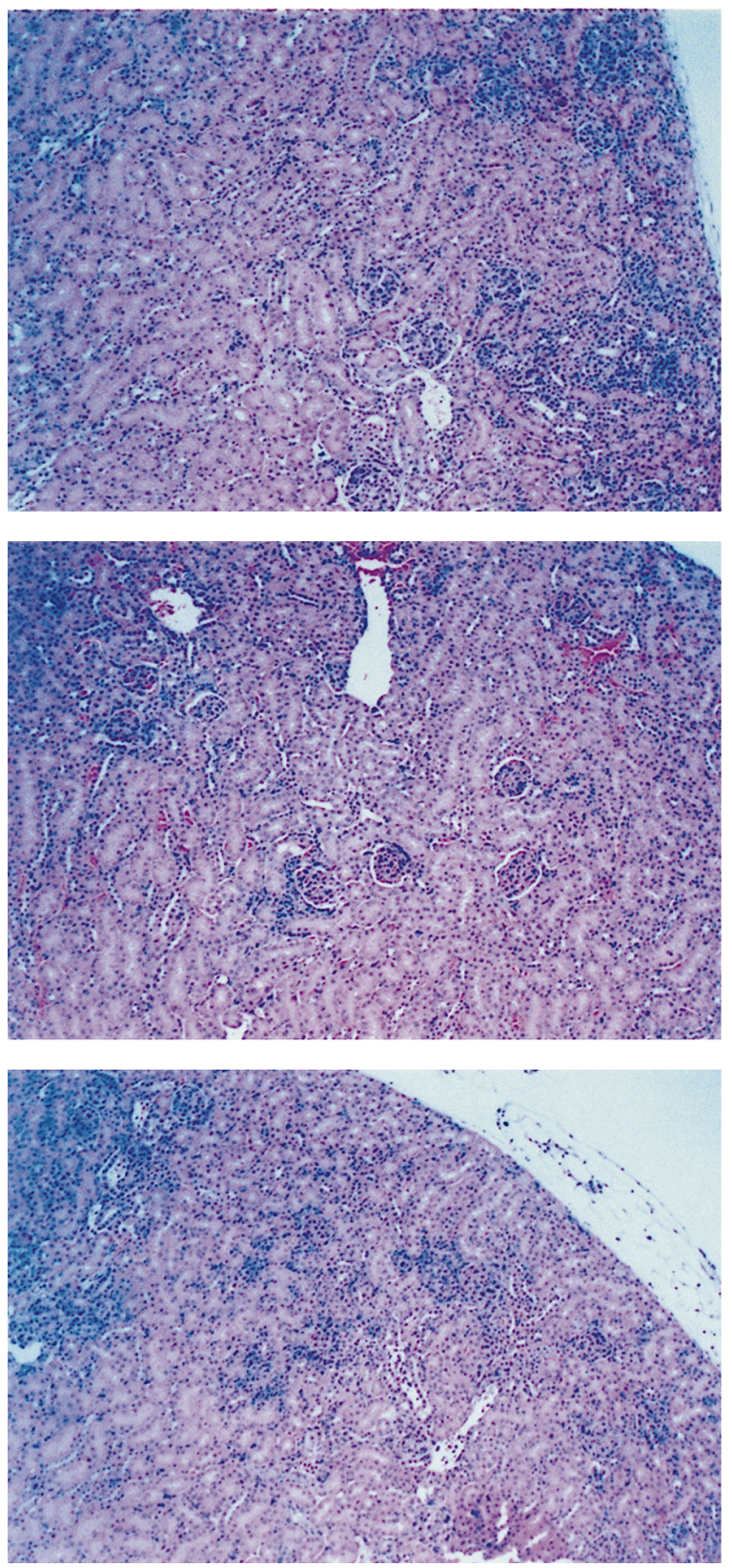

\section{Day 28}
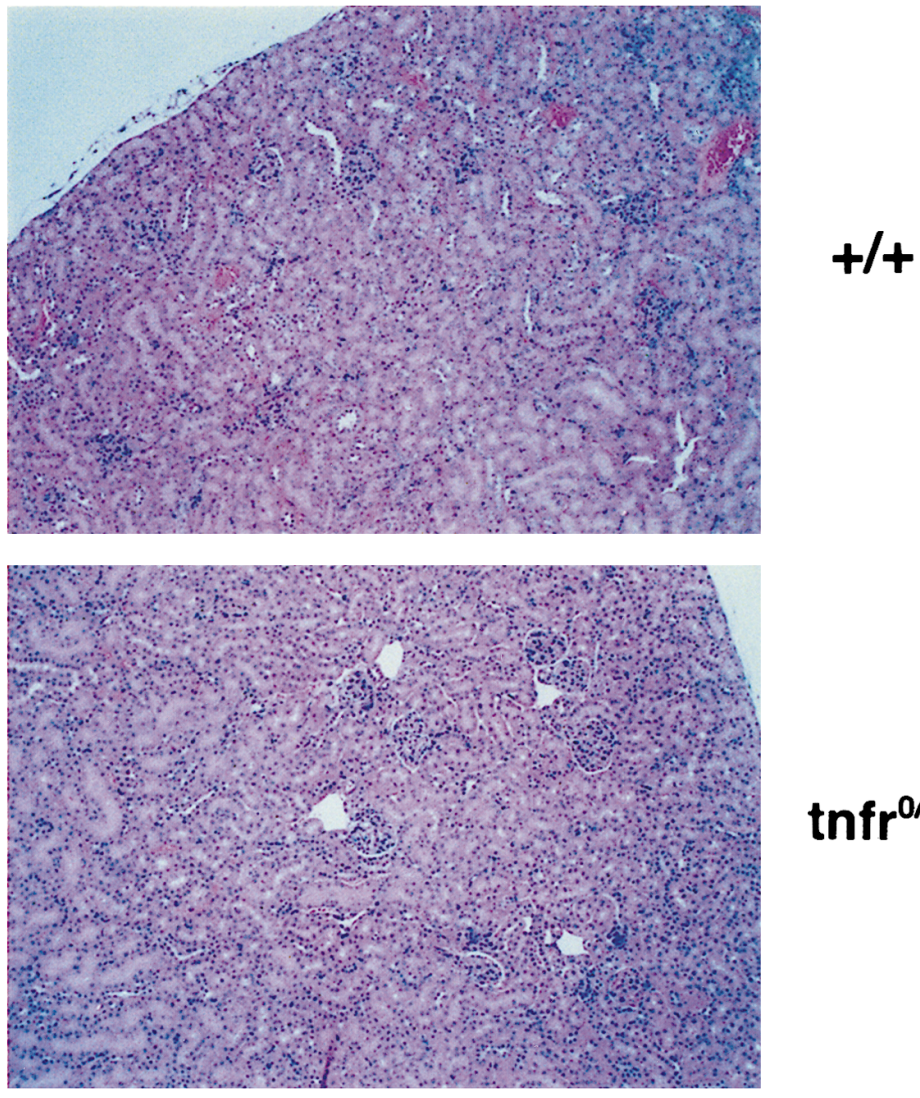

$\operatorname{tnfr} 0 / 0$

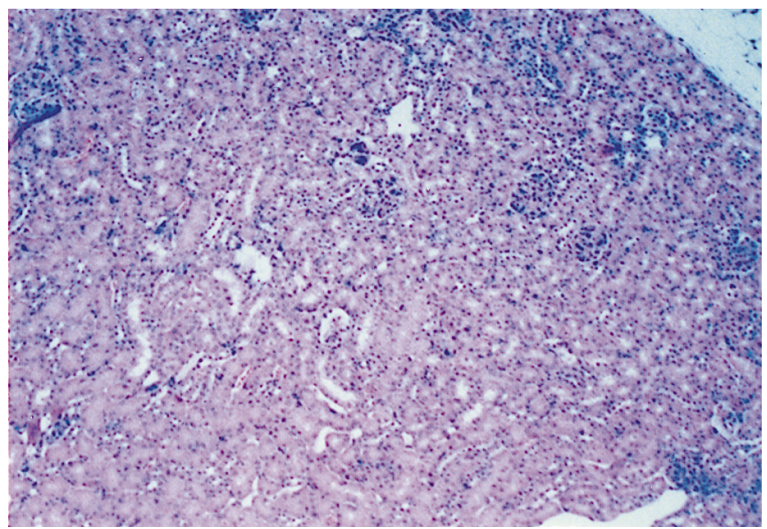

\section{Ipr/Ipr}

Figure 2 (Continued)

tnfr $r^{0 / 0}$ mice. In contrast, extensive infiltration with inflammatory cells but very low apoptosis were present in B6-lpr/lpr mice at days 28 and 100 of MCMV-induced disease, suggesting that a defect in the AICD of lymphocytes in lpr/lpr mice leads to a chronic post-MCMV inflammation.

Apoptosis of peritoneal cells in MCMV-infected mice. Macrophages represent the first line of the host defense after intraperitoneal administration of viruses and it has been demonstrated in different mouse models that impaired macro- phage function leads to increased susceptibility of the host to virus infections $(8,45)$. The data thus far indicated that apoptosis is critical for the elimination of virally infected cells and high numbers of apoptotic cells were found in situ early after MCMV infection. To determine if apoptosis occurs at the site of infection and affects peritoneal macrophages, peritoneal exudate cells were obtained by ravage $7 \mathrm{~d}$ after MCMV infection of B6-+/+, B6-lpr/lpr, B6-tnfr ${ }^{0 / 0}$, and B6-tnfr ${ }^{0 / 0} l p r / l p r$ mice, and analyzed for apoptosis using 7-AAD staining (Fig. 5). 


\section{Day 7}
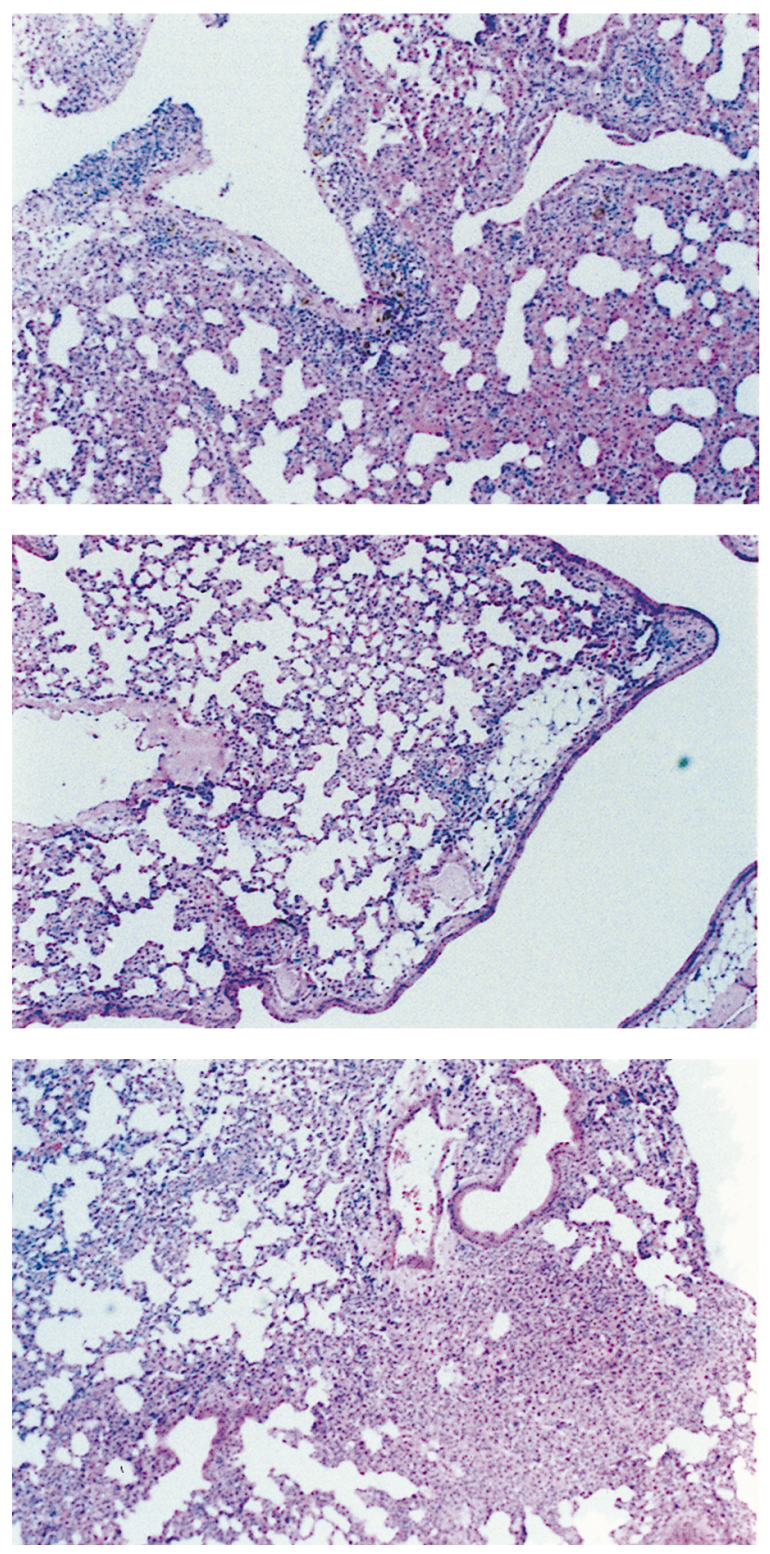

\section{Day 28}
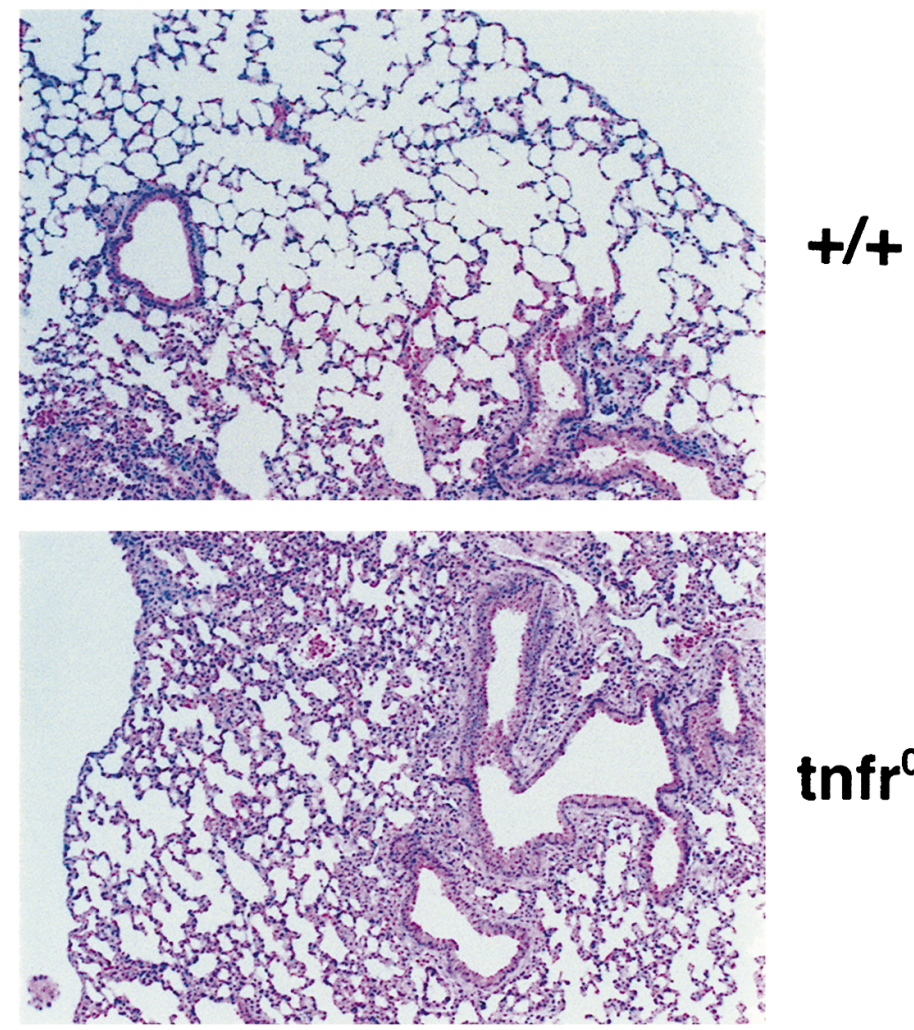

\section{$\operatorname{tnfr}^{0 / 0}$}

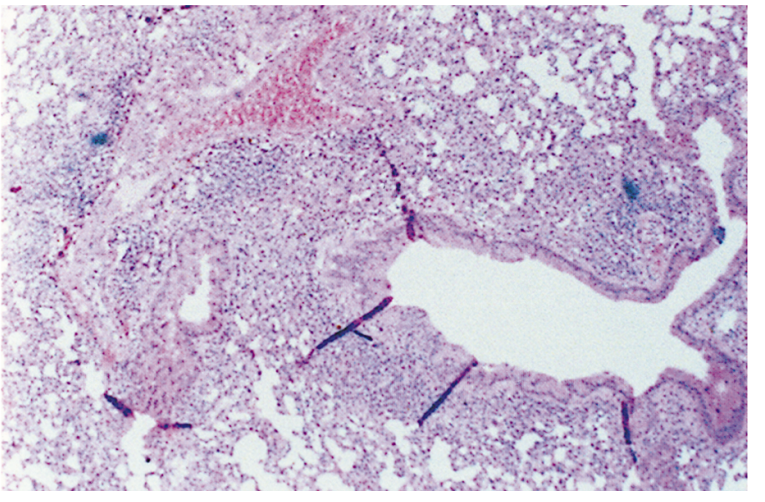

Ipr/Ipr

Figure 2 (Continued)

Large numbers (39\%) of peritoneal cells were undergoing apoptosis in $\mathrm{B} 6-+/+$ mice at this time as indicated by increased 7-AAD uptake. Lower numbers of apoptotic peritoneal cells were present in B6-lpr/lpr mice (15\%) and B6-tnfr ${ }^{0 / 0}$ mice $(11 \%)$. In contrast, very few apoptotic peritoneal cells were found in B6-tnfr $r^{0 / 0}$ lpr/lpr mice (3\%) at the same time point, indicating that substantial apoptosis is associated with rapid clearance of MCMV.

Serum levels of IFN- $\gamma$ and TNF- $\alpha$ after MCMV infection. Analysis of serum levels of cytokines revealed high levels of IFN- $\gamma$ (ranging from 400 to $1,200 \mathrm{pg} / \mathrm{ml}$ ), which were produced early (day 3) after infection, in B6-+/+, B6-lpr/lpr, and B6tnfr ${ }^{0 / 0}$ mice (Fig. 6). Only low levels of IFN- $\gamma$ were found in the same mice by day 7, which is consistent with studies in B6-+/+ mice by other investigators $(9,46)$. However, production of IFN- $\gamma$ was about fourfold higher at day 28 in B6-lpr/lpr mice than in B6-+/+ and B6-tnfr ${ }^{0 / 0}$ mice, which might be due to the activation of $\mathrm{T}$ cells during the chronic inflammatory response. In contrast, IFN- $\gamma$ was produced at very high levels $(2,700 \mathrm{pg} /$ $\mathrm{ml})$ in B6-tnfro/0 lpr/lpr mice and remained high through $28 \mathrm{~d}$ after infection $(1,400 \mathrm{pg} / \mathrm{ml})$. Induction of TNF- $\alpha$ by MCMV was detected early after infection in all mice. However, levels 

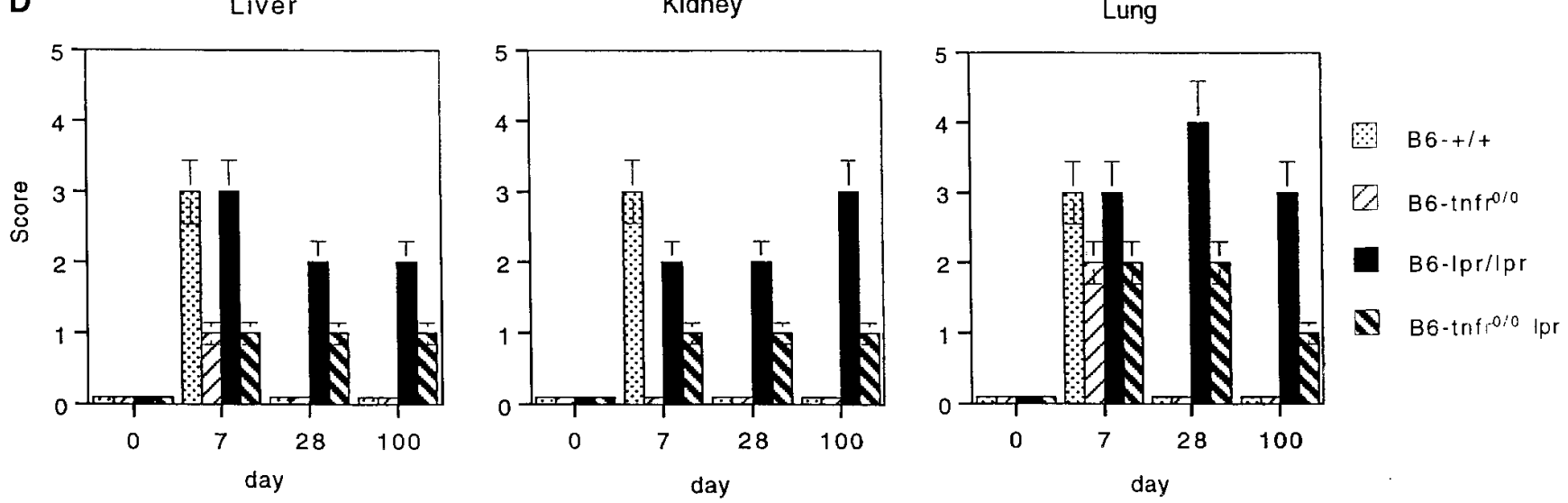

Figure 2 (Continued)

of TNF- $\alpha$ were $\sim 10$-fold higher in the sera of B6-lpr/lpr, B6tnfro/0, and B6-tnfr $r^{0 / 0}$ lpr/lpr mice than that of B6- $+/+$ mice on day 3 and twice as high on day 7 (Fig. 6). This is consistent with our report that production of TNF- $\alpha$ is increased in $l p r / l p r$ mice after stimulation with staphylococcal enterotoxin B (47). Remarkably, TNF- $\alpha$ continued to be expressed at high levels $(80 \mathrm{pg} / \mathrm{ml})$ in B6-lpr/lpr and B6-tnfr ${ }^{0 / 0}$ lpr/lpr mice up to day 28 after MCMV infection.

Enhanced autoantibody production in B6-lpr/lpr mice. To determine if MCMV infection also stimulates autoimmunity, the production of RF and anti-dsDNA antibodies, which are characteristic markers of autoimmune disease, was evaluated $28 \mathrm{~d}$ after MCMV infection. There was a significant induction of RF after MCMV infection in B6-lpr/lpr and B6-tnfr ${ }^{0 / 0}$ mice (Fig. $7 \mathrm{~A}$ ). There was also a two- to threefold increase in the production of anti-dsDNA antibodies in MCMV-infected B6lpr/lpr mice and B6-tnfr ${ }^{0 / 0}$ mice compared with uninfected mice (Fig. 7 B). The expression of RF and anti-dsDNA was increased in uninfected B6-tnfr ${ }^{0 / 0}$ lpr/lpr mice, compared with B6- $+/+$ mice, and was not significantly increased after infection with MCMV (Fig. 7).

\section{Discussion}

Almost three decades ago, Dixon et al. $(48,49)$ and other investigators (50-53) discovered that certain chronic virus infections accelerate autoantibody production and induce immune complex glomerulonephritis in NZB/W mice. T cell tolerance was shown to be critical in maintenance of $\mathrm{B}$ cell nonreactivity in a vesicular stomatitis virus transgenic mouse (54). However, the molecular mechanism describing how a viral infection can lead to a chronic inflammation is not known.

Apoptosis of virally infected cells has been recognized as a critical mechanism by which the host limits virus spread, and the presence of apoptotic cells has been reported during several viral infections, including MCMV $(11,55,56)$. The important role of Fas- and TNF-R1-mediated apoptosis in the elimination of virally infected cells is emphasized by the discovery of potent inhibitors of these pathways by several viruses, which interfere with signaling molecules at different levels of the signal transduction process and thereby prevent apoptosis of the host cell. These inhibitors include the cowpox virus CrmA pro- tein $(57,58)$, the baculovirus protein IAP $(59)$, the E1B $19 \mathrm{~K}$ protein encoded by adenovirus (60), the immediate early genes 1 and 2 of CMV (61), and the recently discovered new family of viral inhibitors (v-FLIP) expressed by several herpes viruses (62). The Fas-Fas ligand and perforin-granzyme pathways also are used by cytotoxic $\mathrm{T}$ lymphocytes during the cytotoxic response for the elimination of virally infected cells $(17,18)$.

These results demonstrate that early apoptosis of virally infected cells is important for the clearance of an acute virus infection in vivo, and involves either the Fas or TNF-R1 pathway. The clearance of MCMV was significantly delayed and low numbers of apoptotic peritoneal cells were observed in B6-tnfro/o lpr/lpr mice. However, the clearance of MCMV in the liver, kidney, lung, and peritoneal exudate was not greatly impaired in B6-lpr/lpr mice or B6-tnfr ${ }^{0 / 0}$ single mutant mice, suggesting a compensatory mechanism involving these apoptosis-inducing molecules. Apoptosis correlated with viral clearance since large numbers of apoptotic cells could be detected in situ in target organs at an early stage during MCMV infection, but no apoptotic cells were present after the clearance of infectious MCMV in B6-+/+, B6-lpr/lpr, or B6-tnfr ${ }^{0 / 0}$ mice. Apoptosis in the liver tissue occurred in scattered cells, and also in clusters containing hepatocytes and $\mathrm{T}$ cells, and some hepatocytes exhibited morphological features characteristic of MCMV infection including cell rounding and nuclear inclusions. It has been reported previously that different virus infections, including herpes viruses, induce increased expression of both Fas and Fas ligand in host cells in vitro $(16,63)$. Together, these results suggest that cell suicide and paracrine killing of infected cells mediated by Fas and TNF-R1 that occur within 1 wk after MCMV entry are important mechanisms for the clearance of MCMV-infected cells. We propose that the first phase for Fas or TNF-R1-mediated apoptosis in response to virus infections is elimination of virally infected cells as depicted in Fig. $8 \mathrm{~A}$.

Fas and TNF-R1 have been demonstrated to mediate apoptosis in activated T cells in vitro $(19,31-34,64-67)$. Although it has not yet been demonstrated formally, it is generally accepted that activation-induced apoptosis exists to maintain immune tolerance (67). The present data extend this concept to the downmodulation of the immune response after resolution of an infectious process. Histological examination of the liver, kidney, and lung at different time points after MCMV infec- 


\section{Liver}

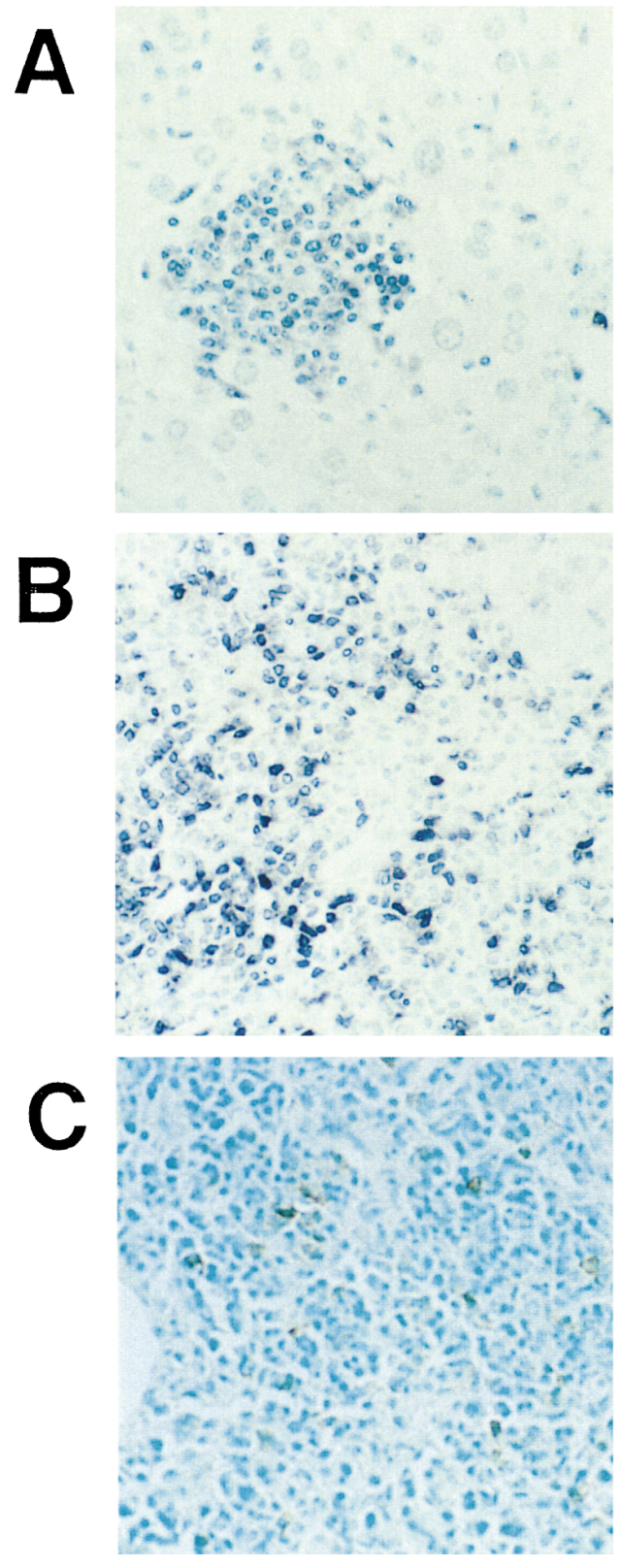

Lung

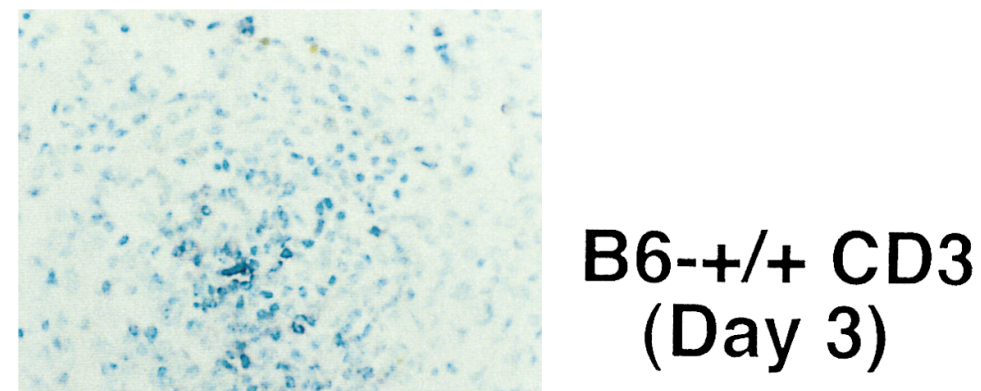

B6-Ipr/Ipr CD3 (Day 28)

\section{B6-Ipr/Ipr B220 (Day 28)}

Figure 3. Immunophenotype of infiltrating cells. Infiltrating T cells in liver and lung of B6- $+/+$ mice $7 \mathrm{~d}$ after MCMV infection $(A)$. Infiltrating T cells in liver and lung during the chronic phase (day 28) of MCMV-induced disease in B6-lpr/lpr mice (B). Expression of B220 antigen in lymphocytes $28 \mathrm{~d}$ after MCMV infection in liver and lung of B6-lpr/lpr mice $(C)$. Original magnification of 320.

tion revealed a severe, chronic inflammatory disease in B6-lpr/ lpr mice, which was characterized by large numbers of infiltrating $\mathrm{T}$ cells. Since chronic disease did not develop in MCMVinfected B6-+/+ or B6-tnfr ${ }^{0 / 0}$ mice, it can be concluded that Fas-mediated, but not TNF-R1-mediated, apoptosis is required for the second phase of apoptosis after the clearance of virus, which eliminates inflammatory cells and leads to the downmodulation of the immune response (Fig. $8 \mathrm{~B}$ ). This concept is supported by the observation that a large percentage of infiltrating $\mathrm{T}$ cells was undergoing apoptosis in B6-+/+ mice $7 \mathrm{~d}$ after MCMV infection, whereas few apoptotic cells were detected in B6-lpr/lpr mice. Excessive inflammation and low apoptosis were not due to a persistent infection in B6-lpr/lpr mice since the clearance of MCMV was not delayed as no infectious MCMV could be detected in the liver, kidney, lung, or peritoneal fluid of these mice at day 28. These results indicate that a defect in Fas-mediated apoptosis may predispose to a chronic postviral inflammatory disease process.

Viral persistence and the inflammatory response are regulated differently by TNF-R1 and Fas. TNF-R1 and Fas signaling are synergistic in regard to viral elimination. Viral elimination can be mediated by either TNF-R1 or Fas since single mutant mice, but not double mutant mice, exhibit nearly normal elimination of virus. TNF-R1 and Fas signaling are antag- 


\section{Day 3}
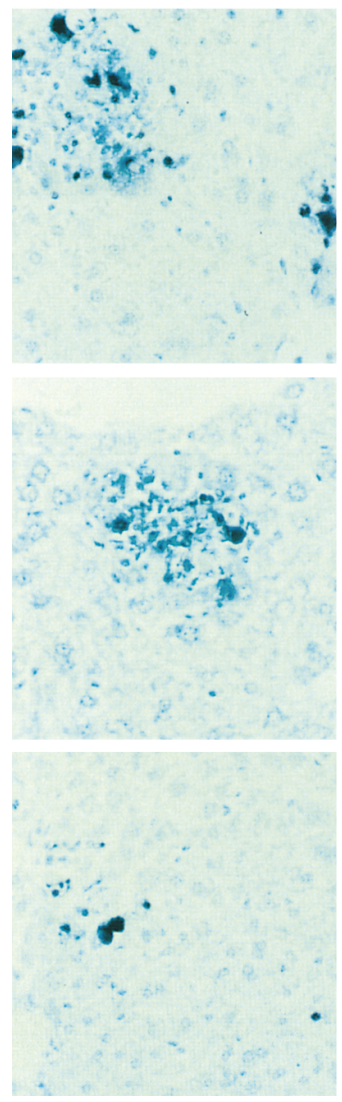

Day 7
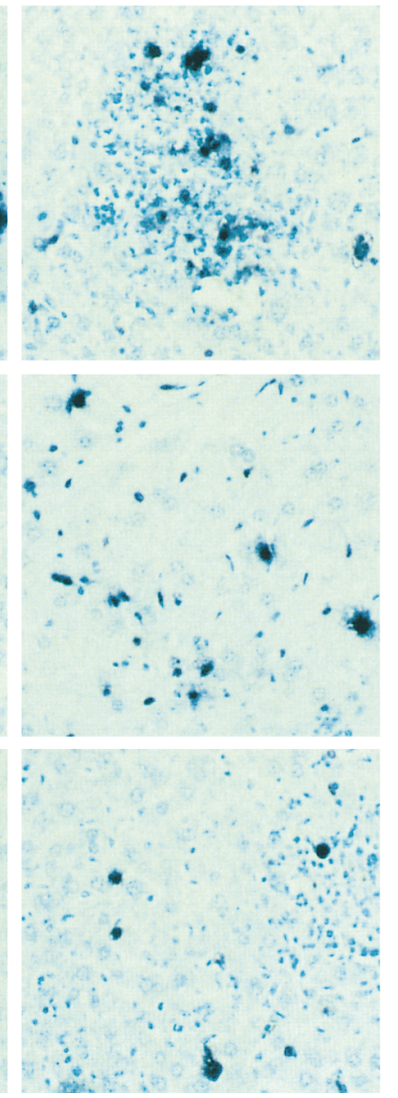

Day 28

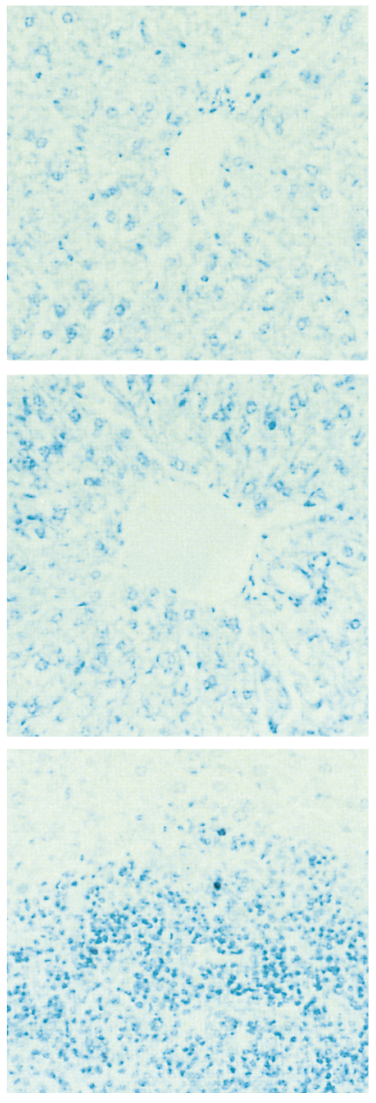

Day 100

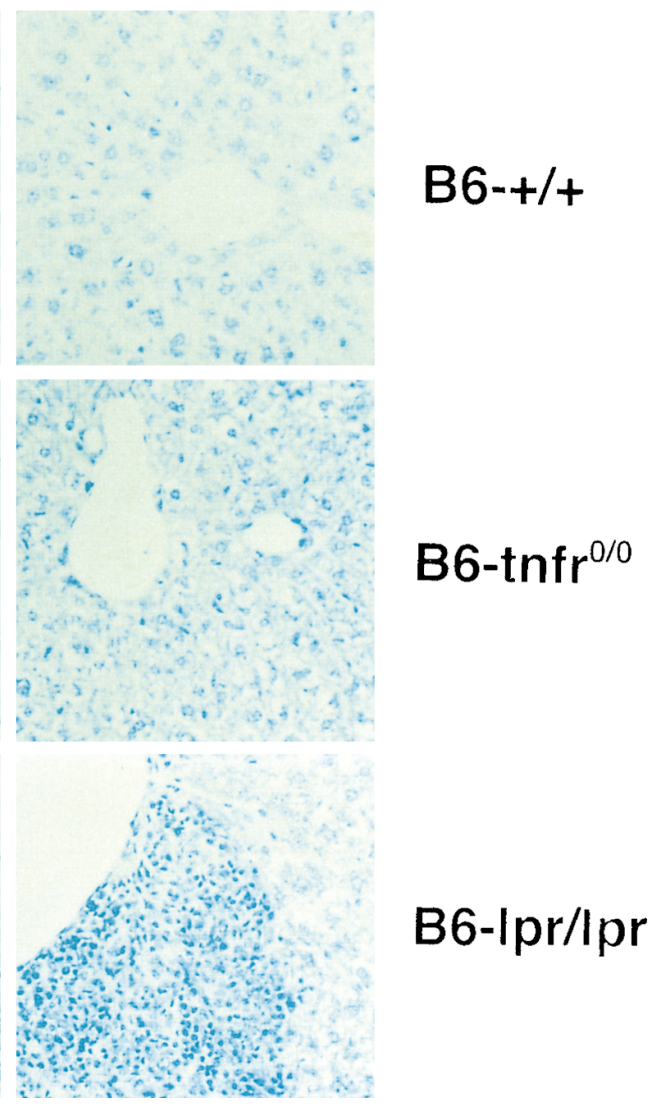

Figure 4. Apoptotic cells in situ. Apoptotic cells were identified by labeling the characteristic DNA-strand breaks using the TUNEL reaction in liver tissue of MCMV-infected B6-+/+, B6-lpr/lpr, and B6-tnfr ${ }^{0 / 0}$ mice at days 3, 7, 28, and 100. Original magnification of 320.

onistic in regard to inflammation. The inflammatory response to the virus is dependent, in part, upon signaling through TNF$\mathrm{R} 1$. This is illustrated by a decreased inflammatory response in both the TNF-R1 single knockout mouse and in the B6-tnfr ${ }^{0 / 0}$ lpr/lpr double knockout mouse. The lack of TNF-R1 signaling results in lower inflammation despite higher virus levels in B6tnfro/0 lpr/lpr mice. In contrast, the absence of Fas is associated with a prolonged inflammatory response. Therefore the lack of Fas signaling, combined with higher virus levels, results in higher inflammation in the B6-tnfr ${ }^{0 / 0} \mathrm{lpr} / \mathrm{lpr}$ mice compared with the B6-tnfro/0 mice.

There is increasing evidence that autoimmune disease can be initiated and promoted by infections, and several hypotheses have been proposed to explain the mechanism by which infectious agents could induce autoimmunity (68). CMV infection has been implicated in several autoimmune syndromes in humans including diabetes mellitus (69), systemic lupus erythematosus (70), Sjögren's syndrome (71), graft versus host disease (72), and rheumatoid arthritis (73). The induction of autoantibodies of various specificities also has been reported after MCMV infection $(74,75)$. High titers of autoantibodies in the $\mathrm{B} 6-\mathrm{Tnfr} 1^{0 / 0}$ mice are consistent with previous results by Jacob et al. that TNF- $\alpha$ treatment decreases autoantibody production in NZB/W strains of mice $(76,77)$. There were high levels of RF and anti-dsDNA in uninfected B6-Tntr $1^{0 / 0}$-lpr/lpr mice, which were not further increased $28 \mathrm{~d}$ after viral infec- tion. This is consistent with our previous observation that B6Tntr $1^{0 / 0}$-lpr/lpr mice develop very high levels of autoantibodies spontaneously which we propose was due to a severe defect in apoptosis to the absence of both TNF-R1 pathway and Fas pathway of apoptosis (23).

Autoimmune disease after CMV and EBV has been described previously (78). However, autoimmune disease is rarely diagnosed in cases in which isolation of infectious virus has been possible (79). Isolation of live virus is difficult since productively infected cells and viral antigens are cleared at different rates by different individuals (80). Moreover, whereas EBV is known to have the capacity to establish a latent infection in B cells, the cell population becoming eventually latently infected during the course of CMV as well as MCMV infection is not clearly defined, and the mechanisms by which latency is established are poorly understood $(81,82)$. Evidence indicates that blood cell progenitor cells in the bone marrow may be a source of latent CMV infection $(83,84)$, and endothelial cells appear to be a potential site of latent MCMV infection (80). Furthermore, MCMV DNA has been detected in several tissues including salivary glands in the absence of infectious virus, again suggesting latent MCMV infection (83-86). Therefore, latent virus may underlie the chronic inflammatory response after MCMV infection.

These results suggest that MCMV infection could trigger autoimmune disease in B6-lpr/lpr mice since significantly in- 
B6-+t+

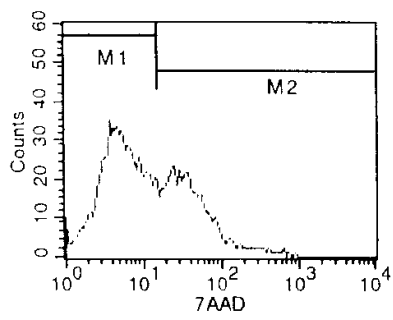

B6- $\operatorname{tnf} r^{0 / 0}$

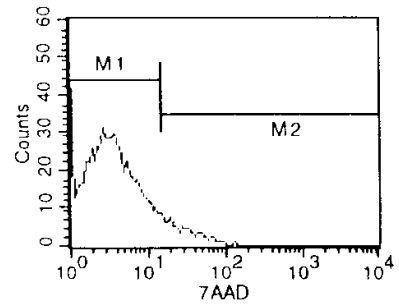

B6-Ipr/Ipr

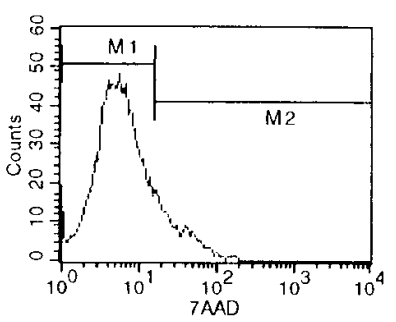

B6-tnfr ${ }^{0 / 0} \mathrm{Ipr} / \mathrm{pr}$

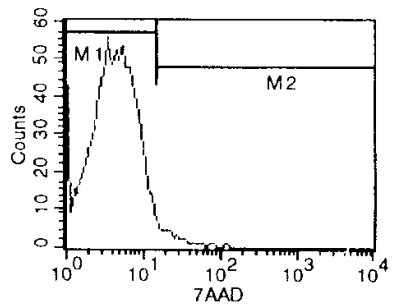

Figure 5. Apoptosis of peritoneal exudate cells in MCMV-infected mice. Apoptosis of peritoneal exudate cells was determined $7 \mathrm{~d}$ after MCMV infection in B6-+/+, B6-lpr/lpr, B6-tnfr ${ }^{0 / 0}$, and B6-tnfr ${ }^{0 / 0} l p r /$ lpr mice by 7-AAD staining. Living cells were 7-AAD negative and are marked as the M1 cell population. Increased 7-AAD uptake indicates apoptotic cells, marked as the M2 cell population. The percentages of apoptotic cells (M2) were: $39 \%$ in B6-+/+ mice, $15 \%$ in B6lpr/lpr mice, $11 \%$ in B6-tnfr $r^{0 / 0}$ mice, and 3\% in B6-tnfro/o $l p r / l p r$ mice.

creased levels of RF and anti-dsDNA autoantibodies were detected, and the histopathological features of the MCMVinduced chronic disease in B6-lpr/lpr mice resembled autoimmune syndromes observed in humans. These results are in accordance with a previous study demonstrating increased numbers of $\mathrm{CD}^{-} 8^{-} \mathrm{B} 220^{+} \mathrm{T}$ cells in B6-lpr/lpr mice after infection with murine leukemia virus suggesting an accelerated progression of the lpr-associated lymphadenopathy (76). In such a scenario, the Fas apoptosis defect in B6-lpr/lpr mice would lead to the accumulation of activated inflammatory cells
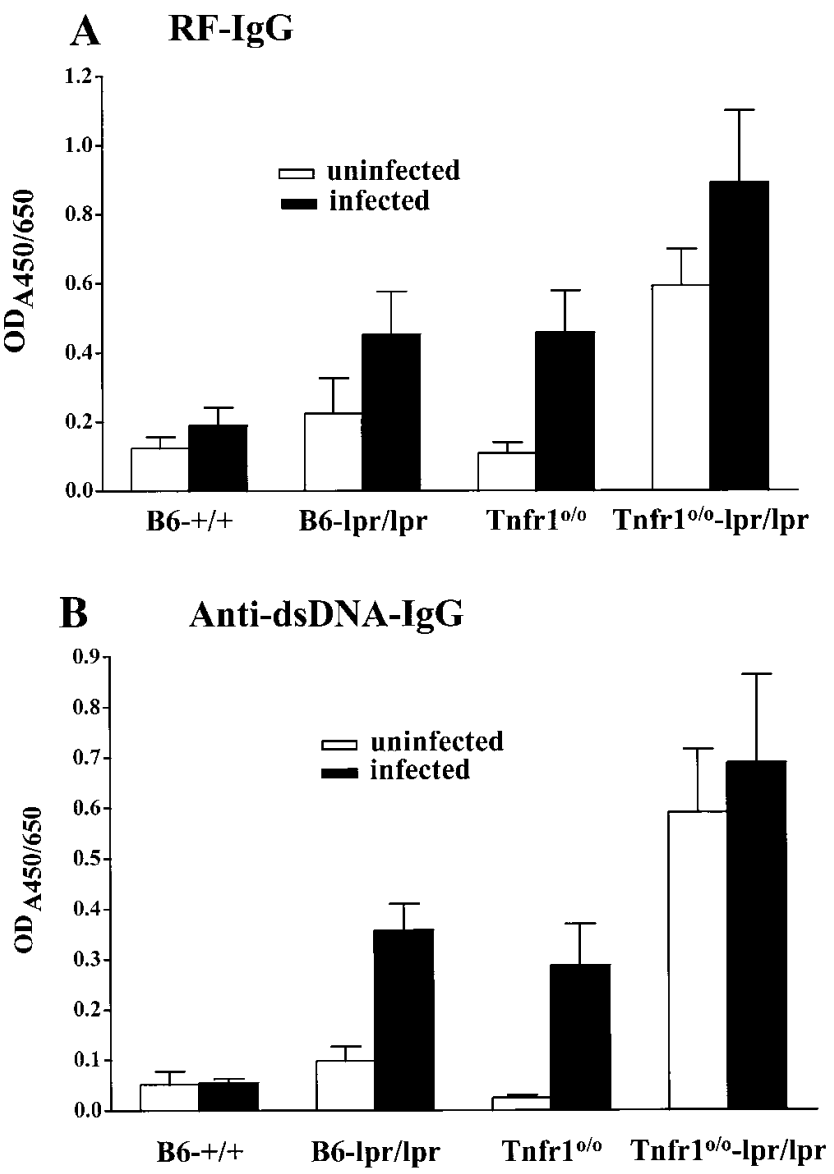

Figure 7. Enhanced autoantibody production in $l p r / l p r$ and $t n f r^{0 / 0}$ mice. Serum levels of RF $(A)$ and anti-dsDNA $(B)$ antibodies were evaluated $28 \mathrm{~d}$ after MCMV infection using specific ELISA assays as described. Each value represents the mean \pm SEM of at least five mice per group analyzed separately.

after the virus infection, resulting in an overproduction of cytokines, which may lead both to a persistent polyclonal activation, including activation of autoreactive $\mathrm{T}$ and $\mathrm{B}$ cells, and to the expansion of the $\mathrm{CD}^{-} 8^{-} \mathrm{B} 220^{+} \mathrm{T}$ cell population causing lymphadenopathy. This model combines a genetic predisposi-

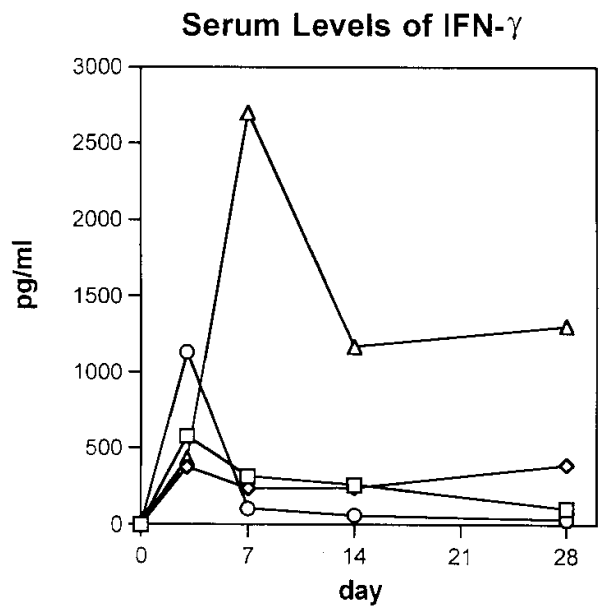

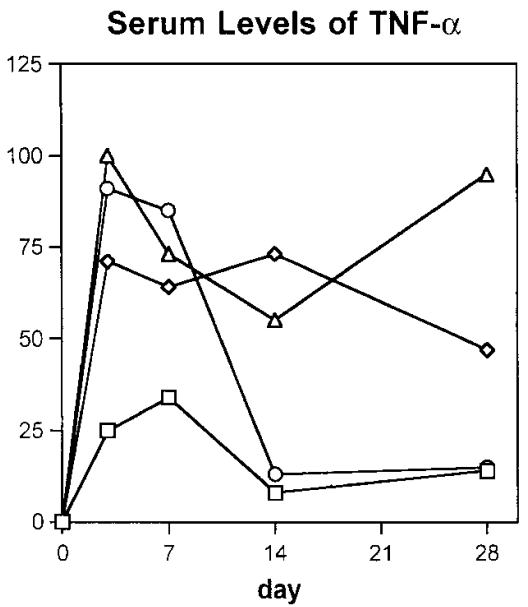

Figure 6. Serum levels of IFN- $\gamma$ and TNF- $\alpha$. Analysis of IFN- $\gamma$ and TNF- $\alpha$ induction was determined in $\mathrm{B} 6-+/+$ (boxes), B6-lpr/lpr (diamonds), B6-tnfro/o (circles), and B6-tnfr ${ }^{0 / 0}$ lpr/lpr (triangles) mice at days $3,7,14$, and 28 after MCMV infection using standard ELISA assays. 


\section{Apoptosis in Virus Infection}
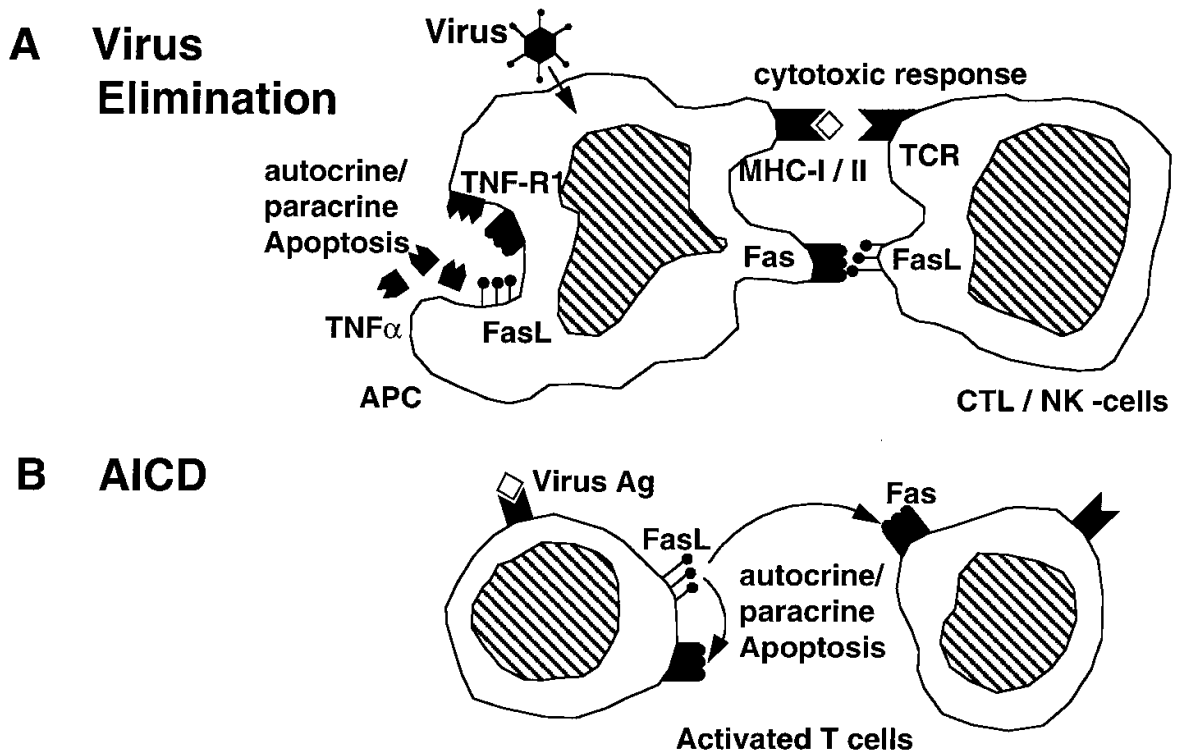

Figure 8. Potential roles of Fas and TNF$\mathrm{R} 1$ apoptosis molecules in virus infections. Phase $1(A)$ : Clearance of virally infected cells by Fas- and TNF-R1-induced suicide, or paracrine killing of infected cells, or apoptosis of the host cell mediated by CTL. Phase $2(B)$ : Fas-mediated AICD is required for downmodulation of the immune response to maintain homeostasis of the immune system.

tion (apoptosis defect) with an environmental trigger (virus infection) and may therefore form an excellent model for analysis of the interplay between these factors in the induction of autoimmune disease in humans.

\section{Acknowledgments}

The authors wish to thank Joyce Palmer for her excellent assistance during the studies and Fiona Hunter for expert review of the manuscript.

This work was supported in part by a Veterans Administration Career Development and Merit Review Award; National Institutes of Health (NIH) grants RO1-AR-42547, NO1-AR-6-2224, and R01 AI30744; a grant from Sankyo, Inc.; a grant from Amgen, Boulder, Inc., Department of Inflammation, provided to Dr. John D. Mountz; and by a grant from the Health Service contract No. NO1-AI-65290 from the National Institute of Allergy and Infectious Diseases, NIH to Dr. Earl R. Kern. Dr. Martin Fleck is supported by a grant from the "Deutsche Forschungsgemeinschaft" (DFG). Dr. Tong Zhou is supported by a grant from the Arthritis Foundation.

\section{References}

1. Britt, W.J., and C.A. Alford. 1996. Chapter 15. In Fields Virology. B.N. Fields, D.M. Knipe, and P.M. Howley, editors. Lippincott-Raven, Philadelphia, PA. 2493-2523.

2. Messerle, M., G.M. Keil, K. Schneider, and U.H. Koszinowski. 1992. Characterization of the murine cytomegalovirus genes encoding the major DNA binding protein and the ICP18.5 homolog. Virology. 191:355-367.

3. Hudson, J.B. 1979. The murine cytomegalovirus as a model for the study of viral pathogenesis and persistent infections. Arch. Virol. 62:1-29.

4. Tanaka, K., Y. Koga, Y.Y. Lu, X.Y. Zhang, Y. Wang, G. Kimura, and K. Nomoto. 1994. Murine cytomegalovirus-associated pneumonitis in the lungs free of the virus. J. Clin. Invest. 94:1019-1025.

5. Quinnan, G.V., J.E. Manischewitz, and F.A. Ennis. 1978. Cytotoxic T lymphocyte response to murine cytomegalovirus infection. Nature. 273:541-543.

6. Selgrade, M.K., Y.S. Huang, J.A. Graham, C.H. Huang, and P.C. Hu. 1983. Humoral antibody response to individual viral proteins after murine cytomegalovirus infection. J. Immunol. 131:3032-3035.

7. Koszinowski, U.H., G.M. Keil, H. Schwarz, J. Schickedanz, and M.J.
Reddehase. 1987. A nonstructural polypeptide encoded by immediate-early transcription unit 1 of murine cytomegalovirus is recognized by cytolytic T lymphocytes. J. Exp. Med. 166:289-294.

8. Heise, M.T., and H.W. Virgin. 1995. The T cell independent role of IFNgamma and TNF-alpha in macrophage activation during murine cytomegalovirus and herpes simplex virus infection. J. Virol. 69:904-909.

9. Orange, J.S., B. Wang, C. Terhorst, and A.B. Biron. 1995. Requirement for natural killer cell-produced interferon- $\gamma$ in defense against murine cytomegalovirus infection and enhancement of this defense pathway by interleukin 12 administration. J. Exp. Med. 182:1045-1056.

10. Banks, T.A., and B.T. Rouse. 1992. Herpesviruses-immune escape artists. Clin. Infect. Dis. 14:933-941.

11. Spriggs, M.K. 1996. One step ahead of the game: viral immunomodulatory molecules. Annu. Rev. Immunol. 14:101-130.

12. Rawlinson, W.D., H.E. Farell, and B.G. Barell. 1996. Analysis of the complete DNA sequence of murine cytomegalovirus. J. Virol. 70:8833-8849.

13. Farell, H.E., H. Vally, D.M. Lynch, P. Fleming, G.R. Shellam, A.A. Scalzo, and N.J. Davis-Poynter. 1997. Inhibition of natural killer cells by a cytomegalovirus MHC class 1 homologue in vivo. Nature. 386:510-514.

14. Kurz, S., H.P. Steffens, A. Mayer, J.R. Harris, and M.J. Reddehase. 1997. Latency versus persistence or intermittent recurrences: evidence for a latent state of murine cytomegalovirus in the lungs. J. Virol. 71:2980-2987.

15. Cuff, S., and J. Ruby. 1996. Evasion of apoptosis by DNA viruses. Immunol. Cell Biol. 74:527-537.

16. Sieg, S., Y. Huang, and D. Kaplan. 1997. Viral regulation of CD95 expression and apoptosis in T lymphocytes. J. Immunol. 159:1192-1199.

17. Lowin, B., M. Hahne, C. Mattmann, and J. Tschopp. 1994. Cytolytic T-cell cytotoxicity is mediated through perforin and Fas lytic pathways. Nature. 370:650-652.

18. Walsh, C.M., M. Matloubian, C.C. Liu, R. Ueda, C.G. Kurahara, J.L Christensen, M.T. Huang, J.D. Young, R. Ahmed, and W.R. Clark. 1994. Immune function in mice lacking the perforin gene. Proc. Natl. Acad. Sci. USA. 91: 10854-10858.

19. Mountz, J.D., T. Zhou, X. Su, J. Cheng, M. Pierson, H. Bluethmann, and C.K. Edwards III. 1996. Autoimmune disease results from multiple interactive defects in apoptosis induction molecules and signaling pathways. Behring Institute Mitteilungen. 97:200-219.

20. Stenger, S., R.J. Mazzaccaro, K. Uyemura, S. Cho, P.F. Barnes, J.P. Rosat, A. Sette, M.B. Brenner, S.A. Porcelli, B.R. Bloom, and R.L. Modlin. 1997. Differential effects of cytolytic T cell subsets on intracellular infection. Science. 276:1684-1687.

21. Cohen, P., and A. Eisenberg. 1992. Autoimmune lpr and gld mice. Ann. Rev. Immunol. 9:243-265.

22. Gilkeson, G.S., P. Ruiz, A.J. Pritchard, and D.S. Pisetsky. 1991. Genetic control of inflammatory arthritis and glomerulonephritis in congenic lpr mice and their $\mathrm{F}_{1}$ hybrids. J. Autoimmun. 4:595-609.

23. Zhou, T., C.K. Edwards III, P. Yang, Z. Wang, H. Bluethmann, and J.D. Mountz. 1996. Greatly accelerated lymphadenopathy and autoimmune disease in lpr mice lacking tumor necrosis factor receptor I. J. Immunol. 156:2661-2665. 
24. Nagata, S. 1997. Apoptosis by death factor. Cell. 88:355-365.

25. Wallach, D. 1997. Placing death under control. Nature. 388:124-126.

26. Lazdins, J.K., M. Grell, M.R. Walker, K. Woods-Cook, P. Scheurich, and K. Pfizenmaier. 1997. Membrane tumor necrosis factor (TNF) induced cooperative signaling of TNFR60 and TNFR80 favors induction of cell death rather than virus production in HIV-infected T cells. J. Exp. Med. 185:81-90.

27. Ando, K., K. Hiroishi, T. Kaneko, T. Moriyama, Y. Muto, N. Kayagaki, H. Yagita, K. Okumura, and M. Imawari. 1997. Perforin, Fas/Fas ligand, and TNF-alpha pathways as specific and bystander killing mechanisms of hepatitis C virus-specific CTL. J. Immunol. 158:5283-5291.

28. Jacob, C.O. 1992. Studies on the role of tumor necrosis factor in murine and human autoimmunity. J. Autoimmun. 5:133-143.

29. Vassalli, P. 1992. The pathophysiology of tumor necrosis factor. Annu. Rev. Immunol. 10:411-452.

30. Rothstein, T.L., J.K. Wang, D.J. Panka, L.C. Foote, Z. Wang, B. Stanger, H. Cui, S.T. Ju, and A. Marshak-Rothstein. 1995. Protection against Fas-dependent Th1-mediated apoptosis by antigen receptor engagement in B cells. Nature. 374:163-165.

31. Alderson, M.R., T.W. Tough, T. Davis-Smith, S. Braddy, B. Falk, K.A. Schooley, R.G. Goodwin, C.A. Smith, F. Ramsdell, and D.H. Lynch. 1995. Fas ligand mediates activation-induced cell death in human T lymphocytes. J. Exp. Med. 181:71-77.

32. Ju, S.T., D.J. Panka, H. Cul, R. Ettinger, M. El-Khatib, D.H. Sherr, B.Z. Stanger, and A. Marshak-Rothestein. 1995. Fas (CD95)/FasL interactions required for programmed cell death after T-cell activation. Nature. 373:444-447.

33. Van Parijs, L., A. Ibraghimov, and A.K. Abbas. 1996. The roles of costimulation and Fas in $\mathrm{T}$ cell apoptosis and peripheral tolerance. Immunity. 4: 321-328

34. Sytwu, H.K., R.S. Liblau, and H.O. McDevitt. 1996. The roles of Fas/ APO-1 (CD95) and TNF in antigen-induced programmed cell death in T cell receptor transgenic mice. Immunity. 5:17-30.

35. Kiener, P.A., P.M. Davis, G.C. Starling, C. Mehlin, S.J. Klebanoff, J.A. Ledbetter, and C.W. Liles. 1997. Differential induction of apoptosis by Fas-Fas ligand interactions in human monocytes and macrophages. J. Exp. Med. 185: $1511-1516$

36. Zimmermann, C., M. Rawiel, C. Blaser, M. Kaufmann, and H. Pircher. 1996. Homeostatic regulation of $\mathrm{CD}^{+} \mathrm{T}$ cells after antigen challenge in the $\mathrm{ab}-$ sence of Fas (CD95). Eur. J. Immunol. 26:2903-2910.

37. Lohman, B.L., E.S. Razvi, and R.M. Welsh. 1996. T-lymphocyte downregulation after acute viral infection is not dependent on CD95 (Fas) receptorligand interactions. J. Virol. 70:8199-8203.

38. Papiernik, M., C. Pontoux, and P. Golstein. 1995. Non-exclusive Fas control and age dependence of viral superantigen-induced clonal deletion in lupus-prone mice. Eur. J. Immunol. 25:1517-1523.

39. Gavrieli, Y., Y. Sherman, and S.A. Ben-Sasson. 1992. Identification of programmed cell death in situ via specific labeling of nuclear DNA fragmentation. J. Cell Biol. 119:492-501.

40. Schmid, I., C.H. Uittenbogaart, B. Keld, and J.V. Giorgi. 1994. A rapid method for measuring apoptosis and dual-color immunofluorescence by single laser flow cytometry. J. Immunol. Methods. 170:145-157.

41. Herndon, F.J., H.C. Hsu, and J.D. Mountz. 1997. Increased apoptosis of $\mathrm{CD}^{4} \mathrm{RO}^{-} \mathrm{T}$ cells with aging. Mech. Ageing Dev. 94:123-134.

42. Zhou, T., H. Bluethman, J. Eldridge, K. Berry, and J.D. Mountz. 1993. Origin of $\mathrm{CD}^{-}{ }^{-} \mathrm{CD} 8^{-} \mathrm{B} 220^{+} \mathrm{T}$ cells in MRL-lpr/lpr mice. J. Immunol. 150:36513667.

43. Shellam, G.R., J.E. Allan, J.M. Papadimitriou, and G.J. Bancroft. 1981. Increased susceptibility to cytomegalovirus infection in beige mutant mice. Proc. Natl. Acad. Sci. USA. 78:5104-5108.

44. Selgrade, M.K., A.M. Collier, L. Saxton, M.J. Daniels, and J.A. Graham. 1984. Comparison of the pathogenesis of murine cytomegalovirus in lung and liver following intraperitoneal or intratracheal infection. J. Gen. Virol. 65: $515-523$

45. Morahan, P.S., S.S. Morse, and M.B. McGeorge. 1980. Macrophage extrinsic antiviral activity during herpes simplex virus infection. J. Gen. Virol. 46: 291-300.

46. Ruzek, M.C., A.H. Miller, S.M. Opal, B.D. Pearce, and C.A. Biron. 1997. Characterization of early cytokine responses and interleukin (IL)-6dependent pathway of endogenous glucocorticoid induction during murine cytomegalovirus infection. J. Exp. Med. 185:1185-1192.

47. Mountz, J.D., T.J. Baker, D.R. Borcherding, H. Bluethman, T. Zhou, and C.K. Edwards III. 1995. Increased susceptibility of fas mutant MRL-lpr/lpr mice to staphylococcal enterotoxin B-induced septic shock. J. Immunol. 155: 4829-4837.

48. Dixon, F.J., M.B. Oldstone, and G. Tonietti. 1969. Virus-induced immune-complex-type glomerulonephritis. Transplant. Proc. 4:945-948.

49. Tonietti, G., M.B. Oldstone, and F.J. Dixon. 1970. The effect of induced chronic viral infections on the immunologic diseases of New Zealand mice. $J$. Exp. Med. 132:89-109.

50. Talal, N. 1977. Immunologic and viral factors in autoimmune diseases. Med. Clin. N. Am. 61:205-215.

51. Gardner, M.B., J.N. Ihle, R.J. Pillarisetty, N. Talal, E.L. Dubois, and J.A. Levy. 1977. Type C virus expression and host response in diet-cured NZB/W mice. Nature. 268:341-344

52. Datta, S.K., N. Manny, C. Andrzejewski, J. Andre-Schwartz, and R.S Schwartz. 1978. Genetic studies of autoimmunity and retrovirus expression in crosses of New Zealand black mice. I. Xenotropic virus. J. Exp. Med. 147:854-871.

53. Haspel, M.V., T. Onodera, B.S. Prabhakar, M. Horita, H. Suzuki, and A.L. Notkins. 1983. Virus-induced autoimmunity: monoclonal antibodies that react with endocrine tissues. Science. 220:304-306.

54. Zinkernagel, R.M., S. Cooper, J. Chambers, R.A. Lazzarini, H. Hengartner, and H. Arnheiter. 1990. Virus-induced autoantibody response to a transgenic viral antigen. Nature. 345:68-71.

55. Yoshida, H., H. Sumichika, S. Hamano, X. He, Y. Minamishima, G. Kimura, and K. Nomoto. 1995. Induction of apoptosis of $\mathrm{T}$ cells by infecting mice with murine cytomegalovirus. J. Virol. 69:4769-4775.

56. Mori, T., K. Ando, K. Tanaka, Y. Ikeda, and Y. Koga. 1997. Fas-mediated apoptosis of hematopoietic progenitor cells in mice infected with murine cytomegalovirus. Blood. 89:3565-3573.

57. Miura, M., H. Zhu, R. Rotello, E.A. Hartwieg, and J. Yuan. 1993. Induction of apoptosis in fibroblasts by IL-1 beta-converting enzyme, a mammalian homolog of the C. elegans cell death gene ced-3. Cell. 75:653-660.

58. Tewari, M., L.T. Quan, K. O'Rourke, S. Desnoyers, Z. Zeng, D.R. Beidler, G.G. Poirier, G.S. Salvesen, and V.M. Dixit. 1995. Yama/CPP32ß, a mammalian homolog of ced-3, is a crm-A-inhibitable protease that cleaves the death substrate poly (ADP-ribose) polymerase. Cell. 81:801-809.

59. Hawkins, C.J., A.G. Uren, G. Häcker, R.L. Medcalf, and D.L. Vaux 1996. Inhibition of interleukin 1 $\beta$-converting enzyme-mediated apoptosis of mammalian cells by baculovirus IAP. Proc. Natl. Acad. Sci. USA. 93:13786-13790.

60. Hashimoto, S., A. Ishii, and S. Yonehara. 1991. The E1b oncogene of adenovirus confers cellular resistance to cytotoxicity of tumor necrosis factor and monoclonal anti-Fas antibody. Int. Immunol. 3:343-351.

61. Zhu, H., Y. Shen, and T. Shenk. 1995. Human cytomegalovirus IE1 and IE2 proteins block apoptosis. J. Virol. 69:7960-7970.

62. Thome, M., P. Schneider, K. Hofmann, H. Fickenscher, E. Meinl, F Neipel, C. Mattmann, K. Burns, J.L. Bodmer, M. Schröter, et al. 1997. Viral FLICE-inhibitory proteins (FLIPs) prevent apoptosis induced by death receptors. Nature. 386:517-521.

63. Sieg, S., Z. Yildrim, D. Smith, N. Kayagaki, H. Yagita, Y. Huang, and D. Kaplan. 1996. Herpes simplex virus type 2 inhibition of Fas ligand expression. J. Virol. 70:8747-8751.

64. Dhein, J., H. Walczak, C. Baumler, K.M. Debatin, and P.H. Krammer. 1995. Autocrine T-cell suicide mediated by APO-1/(Fas/CD95). Nature. 373: 438-441.

65. Brunner, T., R.J. Mogil, D. LaFace, N.J. Yoo, A. Manboubl, F. Echeverre, J. Martin, W.R. Force, D.H. Lynch, C.F. Ware, and D.R. Green. 1995 Cell-autonomous Fas (CD95)/Fas-ligand interaction mediates activation-induced apoptosis in T-cell hybridomas. Nature. 373:441-444.

66. Lenardo, M.J. 1996. Fas and the art of lymphocyte maintenance. J. Exp. Med. 183:721-724.

67. Green, D.R., and D.W. Scott. 1994. Activation-induced apoptosis in lymphocytes. Curr. Opin. Immunol. 6:476-487.

68. Lehmann, P.V., E.E. Sercarz, T. Forsthuber, C.M. Dayan, and G. Gammon. 1993. Determinant spreading and the dynamics of the autoimmune T-cell repertoire. Immunol. Today. 14:203-208.

69. Yoon, J.W. 1990. The role of viruses and environmental factors in the induction of diabetes. Cur. Topics Microbiol. Immunol. 164:95-123.

70. Root-Bernstein, R.S. 1995. Preliminary evidence for idiotype-antiidiotype immune complexes cross-reactive with lymphocyte antigens in AIDS and lupus. Medical Hypotheses. 44:20-27.

71. Thorn, J.J., P. Oxholm, and H.K. Andersen. 1988. High levels of complement fixing antibodies against cytomegalovirus in patients with primary Sjögren's syndrome. Clin. Exp. Rheumatol. 6:71-74

72. Naucler, C.S., S. Larsson, and E. Moller. 1996. A novel mechanism for virus-induced autoimmunity in humans. Immunol. Rev. 152:175-192.

73. Newkirk, M.M., K.N. Watanabe Duffy, J. Leclerc, N. Lambert, and J.B. Shiroky. 1994. Detection of cytomegalovirus, Epstein-Barr virus and herpes virus-6 in patients with rheumatoid arthritis with or without Sjögren's syndrome. Br. J. Rheumatol. 33:317-322.

74. Bartholomaeus, W.N., H. O’Donoghue, D. Foti, C.M. Lawson, G.R Shellam, and W.D. Reed. 1988. Multiple autoantibodies following cytomegalovirus infection: virus distribution and specificity of autoantibodies. Immunology. 64:397-405.

75. Jacob, C.O. 1992. Tumor necrosis factor alpha in autoimmunity: pretty girl or old witch? Immunol Today. 13:122-125.

76. Jacob, C.O., and H.O. McDevitt. 1988. Tumour necrosis factor-alpha in murine autoimmune "lupus" nephritis. Nature. 331:356-358.

77. Price, P., S.D. Olver, A.E. Gibbons, and G.R. Shellam. 1993. B-cell activation following murine cytomegalovirus infection: implications for autoimmunity. Immunology. 78:14-21.

78. Hiromatsu, K., J. Usami, Y. Aoki, M. Makino, and Y. Yoshikai. 1997. Accelerated progression of a murine retrovirus-induced immunodeficiency syndrome in Fas mutant C57BL/6 lpr/lpr mice. Microbiol. Immunol. 41:221-227.

79. Toro, A.I., and J. Ossa. 1996. PCR activity of CMV in healthy CMV-seropositive individuals: does latency need redefinition? Res. Virol. 147:233-238. 
80. Reddehase, M.J., M. Balthesen, M. Rapp, S. Jonjic, I. Pavic, and U.H. Koszinowski. 1994. The conditions of primary infection define the load of latent viral genome in organs and the risk of recurrent cytomegalovirus disease. $J$. Exp. Med. 179:185-193.

81. Kondo, K., H. Kaneshima, and E.S. Mocarski. 1994. Human cytomegalovirus latent infection of granulocyte-macrophage progenitors. Proc. Natl. Acad. Sci. USA. 91:11879-11883.

82. Kondo, K., and E.S. Mocarski. 1995. Cytomegalovirus latency and latency-specific transcription in hematopoietic progenitors. Scand. J. Infect. Dis. 99:63-67.

83. Koffron, A.J., K.H. Mueller, D.B. Kaufman, F.P. Stuart, B. Patterson, and M.I. Abecassis. 1995. Direct evidence using in situ polymerase chain reac- tion that the endothelial cell and T-lymphocyte harbor latent murine cytomegalovirus. Scand. J. Infect. Dis. 99:61-62.

84. Schmader, K., S.C. Henry, R.J. Rahija, Y. Yu, G.G. Daley, and J.D. Hamilton. 1995. Mouse cytomegalovirus reactivation in severe combined immune deficient mice after implantation of latently infected salivary gland. J. Infect. Dis. 172:531-534.

85. Collins, T., C. Pomeroy, and M.C. Jordan. 1993. Detection of latent cytomegalovirus DNA in diverse organs of mice. J. Infect. Dis. 168:725-729.

86. Kurz, S., H.P. Steffens, A. Mayer, J.R. Harris, and M.J. Reddehase. 1997. Latency versus persistence or intermittent recurrences: evidence for a latent state of murine cytomegalovirus in the lungs. J. Virol. 71:2980-2987. 